\title{
ALGUNAS NOTAS SOBRE EL GUSTO DE FELIPE II POR LA ESCULTURA EN SU JUVENTUD A LA LUZ DE NUEVAS CARTAS ENTRE EL OBISPO DE ARRÁS Y LEONE LEONI
}

\author{
POR \\ ALMUDENA PÉREZ DE TUDELA \\ Becaria Universidad Complutense
}

\begin{abstract}
The authoress tries to throw a new light on Philip II of Spain's taste for the Sculpture during the early years as a king with the study of some inedits letters between the sculptor Leone Leoni and the bishop of Arras, future cardinal Granvelle. At the same time, the authoress provides news evidences about the Granvelle's protection to Leoni.
\end{abstract}

Ya Miguel Morán señaló, en dos magníficos artículos ${ }^{1}$, la preferencia que demostraba $\mathrm{Fe}-$ lipe II, mientras era príncipe y durante la primera etapa de su reinado, por la pintura y la arquitectura en detrimento de la escultura. Efectivamente, el único retrato escultórico relevante del Príncipe ${ }^{2}$ no fue un encargo personal, sino de su tía María de Hungría que, cuando ésta fallece en 1558, fue heredado por el ya Rey y que permaneció durante todo su reinado en el taller madrileño de Pompeo Leoni. Salvo las esculturas de gusto arqueologizante que decoraban algunos de sus jardines y que en su mayoría eran regalos, la única ocasión en que Felipe II manifestó un interés sin ambages por la escultura fue con motivo de la decoración de la obra magna de su reinado, El Escorial.

Este estudio, que se inscribe dentro de otro más amplio, pretende esclarecer algunos puntos poco nítidos en las relaciones entre el rey y el escultor que, junto a Tiziano, fue el creador de la imagen de la Casa de Austria durante el siglo xvi. Esta difícil tarea sería imposible

\footnotetext{
1 Morán Turina, M.: «Arqueología y coleccionismo de antigüedades en la corte de Felipe II», en Adán y Eva en Aranjuez. Investigaciones sobre la escultura en la Casa de Austria, cat. exp. M. del Prado, Madrid, 1992, pp. 35-47 y «Sobre el gusto por la escultura en la corte de Carlos V y Felipe II», en Los Leoni (1509-1608). Escultores del Renacimiento italiano al servicio de la corte de España, cat. exp. M. del Prado, Madrid, 1994, pp. 17-28. En este último catálogo, también se encuentra un estudio global sobre los Leoni que recoge la bibliografía más importante hasta el momento y al que nos remitimos: Estella Marcos, M.: «Los Leoni, escultores entre Italia y España», pp. 29-62. Una de las aportaciones más recientes sobre el tema de los Leoni es la de ConTI, P. B.: «Tra modellazione e incisione. Appunti e riflessioni per un percorso nell'opera e nella vita di Leone Leoni», en BALBI DE CARo, S. (ed.): I Gonzaga. Moneta Arte Storia, Mantua, 1995, pp. $388-93$

2 Nos referimos al retrato broncíneo de cuerpo entero conservado en el Museo del Prado (E-272).
} 
si no saliese en nuestra ayuda la figura que actúa casi como factotum en la política cultural tanto de Carlos V como de Felipe II, que no es otro que el obispo de Arrás, a partir de 1561 cardenal Granvela. Antonio Perrenot es quien pone en contacto al Emperador y a su hermana, María de Hungría, con el escultor aretino quien, en 1548, se une al cortejo del Príncipe y le acompaña en su viaje triunfal por Italia y los estados alemanes hasta Spira ${ }^{3}$, donde recibe licencia del Príncipe para adelantarse y esperarle en Bruselas. Felipe II, a lo largo de su periplo italiano, recibió el obsequio de una ciudad de Piacenza en plata ${ }^{4}$ que había sido ejecutada por Leone Leoni ${ }^{5}$ a finales de 1548. A pesar de los elogios que de ella hace Leoni al obispo de Arrás y de mencionarse en el inventario del príncipe de $1553^{6}$, la ciudad, símbolo de la sumisión de Piacenza al entonces duque de Milán, no debió de ser especialmente apreciada por Felipe II, quien la manda desclavar y fundir en 1566. La plata obtenida se entrega al platero Manuel Correa para que realice diversos objetos litúrgicos con destino al Monasterio de El Escorial ${ }^{7}$, desvaneciéndose así todas las esperanzas de Plon, quien confiaba en que apareciese algún día.

Una vez que Carlos $\mathrm{V}$ abdica, en 1555, marcha junto a sus hermanas a su retiro definitivo a Yuste. Ilusamente, pretenden que Leone Leoni les acompañe junto con las esculturas que había conducido hasta Bruselas. El aretino protesta airadamente a sus más íntimos amigos y protectores ${ }^{8}$ aunque, para no dar una negativa rotunda al emperador, parece que finge una re-

\footnotetext{
${ }^{3}$ De ello nos informa una carta que escribe desde la capital belga al gobernador de Milán, Ferrante Gonzaga, el 30 de marzo de 1549, que fue dada a conocer por Ronchinl, A.: «Leone Leoni d'Arezzo», en Atti e Memorie della Reggia Diputazione de Storia Patria per le Provincie Modenesi e Parmensi, VIII (1865), pp. 9-41, V. El propio Ferrante aconseja a Leoni que lleve una medalla del joven Príncipe para presentar a su padre (Armand, A.: Les Médailleurs italiens des quinzième et seizième siècles, París, 1883-87, I, p. 164, n.11.).

${ }^{4}$ La ciudad le fue entregada por un grupo de caballeros piacentinos en Cremona, como nos informa CALVETE DE EsTRELLA, J.C.: El felicissímo viaje del muy alto y poderoso Príncipe Don Felipe..., Amberes, 1552, f. 36. Aunque en un principio se pensó incluir esta ciudad en el itinerario del príncipe, el aún reciente asesinato de Pierluigi Farnesio hace que se posponga la entrada hasta el viaje de regreso.

${ }^{5}$ Leone realiza, junto un tal maestro Antonio, el modelo argénteo de la ciudad de Piacenza entre septiembre y octubre de 1548. Por él recibe 350 escudos. Esta obra está documentada en Plon, E.: op. cit., 1887, pp. 39-40, 250-51 y 353-54 (B.P. , Ms. II/2267, f.158). Sobre este tema y sobre el significado de este obsequio como fructus belli, veáse SoLDINI, N. «Strategie del dominio: la cittadella nuova di Piacenza (1545-1556)», en Bolletino Storico Piacentino, LXXXVI (1991), pp.
} $11-69$.

${ }^{6}$ Morán, M. y CHECA, F.: El coleccionismo en España. De la cámara de maravillas a la galería de pinturas, Madrid, 1985, p. 81, donde se data el inventario en 1554. CHECA, F.: Felipe II. Mecenas de las artes, Madrid, 1992, p. 88, se refiere a «un modelo de la ciudad de Plasencia en Lombardía», fechando el inventario aludido un año antes. Se conserva en el Archivo General de Simancas (A.G.S.), Contaduría Mayor de Cuentas (C.M.C.), 3. a época, leg. 53, no 39, 15 v. El asiento del inventario, junto a las descripciones que hace Leoni a Granvela, pueden proporcionarnos una idea bastante aproximada de esta obra: «un modelo de la ciudad de Plasencia de Lombardia con el castillo nuevo dorado todo de plata entiendese e suelo asentado sobre madera de chapas de plata y los edificios que se muestran encima deste suelo son también de plata y estan asentados sobre madera esta dividido y partido por medio y metido en dos cajas de madera forradas en raso quermesi y vaqueta colorada lo qual no se puede pessar y por esto no se pone el pesso della».

${ }^{7}$ En la cuenta con Manuel Correa, platero de su magestad, correspondiente al año 1566 y custodiada en el Archivo General de Palacio (A.G.P. ), Madrid, Secc. Administrativa, Cuentas Personales, Plateros y Diamantistas, leg. 5261, leemos que se le carga «la plata que riçivio del modelo de la çiudad de plasençia que se desclabo por mandado de su $m^{t}$ y se hundio En diez y seis de hebrero de mill e qui ${ }^{\circ}$ y sesenta y seis y se allo que era plata de ley de sesenta rreales y un quartillo de manera que le faltava para llegar a la ley de plata de marcar quatro reales y tres quartillos...». El 30 de abril de 1566, había realizado un acetre y dos ciriales de plata la cual «se le dio de lo que se hundio del modelo de la ciudad de plasencia». El 20 de septiembre de 1566, con destino a la plata de capilla del monasterio de San Lorenzo el Real, hizo una cruz acompañada de dos candeleros, dos vinajeras, un portapaz con la Virgen con el Niño y un serafín, un ostiario - que debió rehacer por resultar demasiado pequeño-, una campanilla y una fuente pequeña lisa, «las quales piezas hizo de la plata que se hundio del modelo de la ciudad de plasencia». Todos estos objetos litúrgicos se localizan en ZarCo CUEvas, Fr.J.: Inventario de las alhajas, estatuas, pinturas y tapices y otros objetos de valor y curiosidad donados por el rey don Felipe II al Monasterio de El Escorial. Años de 1571 a 1598, Madrid, 1930, pp. 32 (86, 87, 88, 89), 50 (302), 71 (415), ¿65 (358)? Aunque aparecen en la entrega de 1571, fueron llevadas al Monasterio poco después de ser labradas, en noviembre de 1566 (A.G.P. , Patronato de S. Lorenzo, leg. 1.995, f.12r. y v.).

${ }^{8}$ Por ejemplo, en la carta que envía a Ferrante Gonzaga, desde Bruselas, el 1 de agosto de 1556, leemos:»l'Imperadore vuolmi in Hispagna, et io non credeva d'aver meritato tanto male per haver così ben servito», RoNCHINI, A.: op. cit., 1865 
pentina enfermedad que le impide seguir a su patrón y que le obliga a regresar a Milán. En su lugar, envía a su hijo Pompeo que establecerá su taller en Valladolid, donde se encargará de terminar las esculturas y retocar los desperfectos que éstas sufrieron durante el viaje. Esta actividad se prolongará durante buena parte del reinado de Felipe II, sin que éste parezca mostrar excesiva prisa en verlas acabadas, al contrario de lo que ocurrirá posteriormente con las esculturas broncíneas destinadas al retablo y cenotafios reales escurialenses.

Es en este momento y hasta el traslado de la corte a Madrid, cuando vamos a centrar nuestro estudio que nos revelará, también, algunos datos sobre el apasionado amor al arte de Granvela, incluso por encima del servicio y fidelidad a su señor en materia artística, que no política. La primera carta (Ap. doc. I) que aportamos es la respuesta de Granvela a otra que le había enviado Leoni desde Milán el 24 de enero de $1557^{9}$. En ella se preocupa por la salud del escultor, que desde su llegada ha pasado la mayor parte del tiempo convaleciente en su lecho, y le promete ayudar en varias cuestiones administrativas como son las cartas que ha enviado al cardenal de Trento y al presidente del senado milanés en favor del caballero Vendramín y de Battista Rosatto ${ }^{10}$, respectivamente. La respuesta de Leoni no se hace esperar, ya que le contesta el 18 de marzo (Ap. doc. II) y, en agradecimiento a las molestias que se ha tomado con él Granvela, le promete compensar con lo que verdaderamente interesaba al prelado, esculturas. Leoni comunica al obispo que dentro de un año tendrá totalmente terminadas las esculturas broncíneas ${ }^{11}$ que le pide, pues ya están fundidas y sólo falta pulirlas, tarea que le resultaría

p. 38, XXII. Sin embargo, Ferrante Gonzaga considera esta invitación un honor para el escultor. Cuando Leone le escribe, desde Milán, el 20 de enero de 1556 (Ronchini, A.: op. cit., 1865, p. 35, XVIII) anunciándole que ha sido llamado a Bruselas por sus patronos, Ferrante lo interpretará como un espaldarazo en la carrera del escultor: "A leone Aretino/ Tre di fa' hebbi la lra vra de XX, et hoggi ho ricevute le tre medaglie che mi havete mandate, le quale [tachado: da] me sono state gratiss, per la bella, et ingeniosa fatica che vi havete fatta dentro, cosi nel dritto come nel rovescio, del qual voi non vi potevi gia imaginar ne il più bello ne il più propio a la Fortuna che io ho corsa, ve ne rendo adunque infinite gratie et mi rimetto appersso a dimostrarvi con effetti qnto io mi tenga per obligato à la virtu et amorevolezza vra [tachado: il qual obligo] la qual obligne serà in effetto compiuta se tra le molte occupationi che de ragione dovete haver in $q^{\text {to }}$ vro partir rubbarete tanto di tempo per amor mio poserate farme et mandarmene due ó tre altre megliore et perfette et qnto al getto, poi che quelle che mi havete mandate in $q^{\text {ta }}$ parte, non sono riuscite troppo bn' come voi med dite onde io vorrei gia rima-

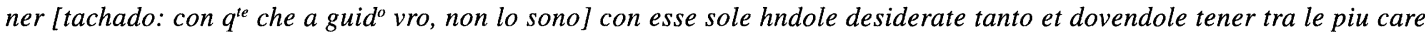
cose ch'io ne habbia. Et di cio potrete esser certo de dovermi far tal piacere, et obligar'di maniera ch'io non perdrò occasione onde vegga di potervene mostrar ogni gratitudine come piu a pieno vi dirà il sec ${ }^{\circ}$ Giul ${ }^{\circ}$ a cui le potrete poi consegnar per che egli me le mande come ha fatto qte altre. De l'andata vra in Corte me rallegro con voi, come di cosa, che se bn' sa' $q^{t i}$ princippi vi da travaglio, v'apportarà al fine honore, et utile Nel che vi potrete di me prometter' sempre tutto quello ch'io potrò far per [tachado: benefi] voi, sicuro di non dover rimaner punto ingannato di qnto di me vi prometterete. Non mancherò di farvi qnto prima liberar del fastidio che vi da il Marino per le cento scudi che faceste prestar a ms. Lud ${ }^{c o}$ Montio, et senza più mi risposerò (?)», Minuta de Ferrante Gonzaga a Leone Leoni (Milán), Mantua, 29 de enero de 1556, Archivio di Stato di Parma (A.S.Pr.), Epistolario Scelto, busta (b.) 23 (scultori), ad vocem. La medalla a la que alude Gonzaga es aquella con el reverso de Hércules orlado por la inscripción «TV NE CEDE MALIS» (ARMAND, A.: Op. cit., 1883-87, I, p. 164).

9 Plon, E.: op. cit., 1887, pp. 379-80, n.61. En ella Leoni relata a Granvela su penoso viaje desde Alemania a Milán, a donde llegó cuatro días antes de navidad, y le pide una carta de recomendación para un deudo suyo que quería encargarse de la Portería del Senado de Milán y otra para el caballero Vendramino, sobre los cuáles ya estará un memorial en manos del obispo.

${ }^{10}$ Estas cartas son solicitadas por Leoni en una misiva de septiembre de 1556, en la que explica qué vínculos le unen con estos personajes. Fue dada a conocer por PLON, E.: op. cit., 1887, p. 379, n. 60.

11 Una idea sobre las esculturas en las que estaba trabajando Leoni antes de partir hacia Bruselas, nos la proporciona la carta escrita por Gian Battista Castaldo a Granvela, fechada en Milán el 12 de febrero de 1556, en la que se lamenta de no haberse ido: "con lione aretino et mastro gianello [Turriano] (...) ma posso io ben dolermi del aretino che non mi ha lassato un ritratto de v.s. et io la supp ${ }^{c o}$ a mandarmene [anotación en el margen: ritratto mio] uno in tela poi che da lui non lo ho possuto aver in marmo o bronzo», Biblioteca Nacional de Madrid (B.N.M.), Mss. Caja 7906, f.124. En el f.163, resumen del secretario de Granvela: "vorria venir con leone/che gli mandi in tela un ritratto mio poiche di leone non le ha potuto haver'ny de marmo ny de bronzo». M.A. Patanella, ecónomo de Milán, también poseía "una mezza statua di v.s. [Granvela] che adorna il piu bello loco de la loggia» de su casa milanesa, como informa en una carta que escribe al obispo el 7 de abril de 1556 (B.P. , Ms. II/2307). Posiblemente, Leoni se refiera a un nuevo encargo escultórico encomendado por el prelado durante su reciente estancia en la corte. Ya Leoni había hecho llegar al obispo, en los inicios de 1556, varias 
más fácil si contase con alguna ayuda. La carta da a entender que Ferrante Gonzaga, que se encontraba en ese momento en Bruselas, adonde había sido llamado por Felipe II para participar en la batalla de San Quintín ${ }^{12}$, le había pedido unos pequeños bocetos, indispensables en el arte de la escultura en bronce ${ }^{13}$, para enseñárselos al Rey. Para finalizar, se remite a lo que informará Gonzaga sobre las esculturas y se disculpa por no enviarle otros dibujos por el tiempo que esta tarea le habría apartado de su trabajo. Esta última noticia, aunque desconocemos a qué proyecto escultórico se refiere, reviste una especial importancia ya que parece indicar la intención de Ferrante Gonzaga y de Leoni de despertar el interés regio en una nueva empresa escultórica. Aunque el que no se llegase a realizar la escultura ecuestre de Carlos V que proyectaba Ferrante Gonzaga se haya achacado a la negativa imperial ${ }^{14}$, parece que lo que realmente contestó Carlos $\mathrm{V}$ al entonces gobernador de Milán fue que aplazase el proyecto para que Leoni se pudiera dedicar a las esculturas que necesitaba María de Hungría para su galería

esculturas broncíneas que le fueron comisionadas en su primer viaje a Bruselas. Éstas eran los bustos del cardenal, Carlos V y María de Hungría, junto con un relieve oval con el retrato del Emperador. Otro encargo que se ha relacionado con el escultor es el busto relicario de san Lorenzo ofrecido por Granvela a la iglesia parroquial de Ornans junto a un busto de bronce con su efigie hoy perdido. Sobre esta última referencia, veáse CurIE, P. : «Quelques portraits du cardinal de Granvelle», en Brunet, J. y Toscano, G. (eds.): Les Granvelle et l'Italie au XVI siècle: le mécénat d'une famille. Actes du Colloque international organisé par la Section d'Italien de l'Université de Franche-Compté, Besançon, 2-4 octobre 1992, Besançon, 1994, p. 172, nota 10. Sin embargo, la Doct. Margarita Estella, en su artículo «Algo más sobre Pompeyo Leoni», en A.E.A., 262 (1993), p. 138, no ve la mano de Leoni en la ejecución de este busto relicario.

${ }^{12}$ Ferrante Gonzaga era uno de los nobles italianos más apreciados por Carlos V que le nombró gobernador de Milán. La admiración era mutua, pues Ferrante ideó erigir una estatua ecuestre en honor del Emperador gracias a la cual el César entra en contacto con el escultor. Sin embargo, es acusado ante Carlos V y decide ir personalmente a Bruselas a defenderse ante el Emperador. Tras este episodio, se refugia en Mantua donde permanece hasta que Felipe II le reclama en Flandes, donde morirá el 15 de noviembre de 1557. Todos estos datos biográficos nos los aporta Gosellini, G.: Vita del Principe don Ferrante Gonzaga, Milán, 1574. Una prueba de la relación entre el escritor, secretario de Ferrante Gonzaga, Granvela y Leoni, es la carta que envía Granvela desde Bruselas, el 13 de noviembre de 1549, a Gosellini en mano de ms. Leone Aretino al que recomienda (A.S.Pr., Carteggio Farnesiano, Estero, Paesi Bassi, b. 106, fasc. 1546-49, f.105). También se conservan, aparte de los testimonios publicados por Plon, diversas cartas de Gosellini a Granvela refiriéndose a Leoni en la B.N.M., Mss. Caja 7909, ff. 89 (17-I-1551), 90 y 91 (19-X-1556).

${ }^{13}$ Cuando se ejecutaron las otras esculturas que hoy conocemos, también se usaron dibujos que servirían a la familia imperial para imaginarse cómo serían sus esculturas una vez acabadas. Éstos aún se conservaban a la muerte de Felipe II y se mencionan entre los bienes reales en poder del arquitecto Francisco de Mora: «Idem se le cargan al dho franc ${ }^{\circ}$ de Mora un papel con tres Retratos, dos el Emperador y uno de la $R^{\text {na }} M a^{\text {ria }}$ [de Hungría] de medio cuerpo, y otro papel de un retrato entero del Rey nro sor, otro papel con otro retrato entero del Emperador con el Turco aprissionado y otro papel con otro retrato de la $R^{\text {na }}$ Leonor entero y otro papel con otro retrato entero del Rey nro $s^{\text {or }}$ y otro papel con otro retrato entero de la Emperatriz $D^{a}$ Ysabel nra señora y otro papel con otro retrato entero del emper ${ }^{o r}$ nro sor , y otro papel con una Tarxeta, $y$ otro retrato de medio cuerpo del emperor nuestro señor y debaxo otro de la emperatriz $D^{a} Y$ Yabel nra $S^{a}$, y otro retrato de medio cuerpo, de la misma emperatriz todos de azul claro, obscuro y de dibujo que se hizieron para hazer por ellos los Retratos enteros de bulto que se hiz ${ }^{o n}$ de marmol y bronze que están en las bovedas del çierso", A.G.P., Secc. Administrativa, leg. 919, Discriptiones cartas plantas y mapas que están en la pieza de la Torre de la sala grande, f. 115 . Estos dibujos resultan de gran interés al mencionar un boceto para una escultura de cuerpo entero de la reina Leonor, hermana de Carlos V y tía de Felipe II, que no se cita en los inventarios de las esculturas que tenía P. Leoni en su taller en 1608, pero a la que también hace referencia Vasari en el elenco de las obras que realizó Leoni con destino a la galería de retratos de Binche. También, algunas esculturas en terracota podrían tener este valor como bocetos, por ejemplo, el busto en este material del Emperador que entra a formar parte de los bienes en Bruselas de Felipe II en 1556 y que, anteriormente, pertenecía a Carlos V. Sobre este inventario, nos remitimos a PINCHART, A.: «Tableaux et sculptures de Charles-Quint (1556)», en Revue Universelle des Arts, 1856, p. 236.

${ }^{14}$ Por ejemplo, Morán, M.: op. cit., 1994, p. 18, aduce como prueba la carta que escribe L. Leoni a Ferrante Gonzaga, fechada en Bruselas el 30 de marzo de 1549, en la que le transmite la confidencia que le ha hecho Granvela sobre la opinión de Carlos V respecto a la escultura ecuestre: "di là a tre o quattro giorni mi ha fatto domandare [Carlos V], et al longo s'è pigliato piacere di ragionare con meco circa a la opinione che V.Ill. ${ }^{\text {ma }} S$. ha sopra al far delle statue. Ma io, che di buona sorte era informato da Mons. ${ }^{r}$ d'Aras qualmente la M. ${ }^{\text {tà }}$ Sua non voleva così liberamente scuoprirse d'haver accetto questa memoria per non parere cotanto ambitioso, gli dissi quanto sarebbe l'opinione di V.S.Ill. ${ }^{\text {ma }}$ S., et quanto si doveva, et per che conto: di che esso Imperadore mi comandò, dopo i discorsi si dell'essere armato come vestito, o modernamente o all'antica, che io ne facessi il modello, come era l'animo di V.Ecc. che si facesse: sì che a questa prima parte non si poteva far più di questo; et tutto starà bene et faravvisi honore», Ronchini, A.: op. cit., 1865, p. 26, V. Sin embargo, lo que parece deducirse de esta carta es que el proyecto seguía adelante. 
de retratos familiares en el palacio de Binche ${ }^{15}$. Quizá lo que propondría Ferrante Gonzaga a Felipe II en 1557 era retomar la idea de la escultura ecuestre, u otra de similar significado, para perpetuar la memoria del césar ya que, en estas fechas, las esculturas por las que Carlos $\mathrm{V}$ había aplazado la del caballo estaban casi acabadas.

La última carta que escribe el entonces obispo de Arrás en el año, el 12 de diciembre, tras la campaña de San Quintín (Ap. doc. III), es la respuesta a una del escultor del 29 de junio ${ }^{16}$. En ella, se refiere a asuntos pecuniarios, tan frecuentes en la correspondencia de los artistas, y le promete que agilizará las gestiones, escribiendo al gobernador de Milán, para que el aretino reciba su pensión. También, le comunica que, hasta el momento, no tiene noticias de Pompeo, pero que está seguro de que se comportará cómo Leoni desea y se conduele de la enfermedad del escultor.

El asunto que ocupa la correspondencia del año siguiente, 1558, es la prisión, acusado de luteranismo, de Pompeo. Leone, apelando a la amistad que le une al obispo, le suplicó que intercediese ante Carlos V por él. Granvela ${ }^{17}$ se apresura a escribir una carta a Juan Vázquez (Ap. doc. IV) en la que alaba el virtuosismo de Pompeo como escultor que, andando el tiempo, igualará o sobrepasará al de su progenitor, a la vez que pide como favor personal que se pasen por alto sus faltas ante el temido tribunal inquisitorial. Esta carta es muy significativa de la pasión del futuro cardenal por las artes y de su gran aprecio por Leoni, que si se introduce con tan buen pie en la corte es por la protección incondicional del prelado que le ayuda a superar todas las barreras. Lo que más llama la atención de la carta es que Granvela, cuya política en los Países Bajos junto a la Gobernadora Margarita de Parma se caracterizaría por su intransigencia en materia religiosa y por el celo con que perseguía cualquier atisbo de protestantismo ${ }^{18}$, en el caso del hijo de su escultor preferido, califica su grave falta de «livianidades» cometidas por su excesiva juventud. Para suavizar el asunto, promete que Pompeo, quien quizá se impregnó de aquellas maliciosas ideas en sus dos viajes a Bruselas atravesando Alemania, se arrepiente sinceramente y retracta de sus errores inconscientes para concluir con que, si estos argumentos no eran suficientes, se le levantase la pena porque "se hará en esto muy grande [merced] al padre y la merece por su arte y habilidad y por lo mucho que en ella ha servido a sus magdes». Posiblemente, el apelar al arte del escultor como mérito no sería muy

\footnotetext{
15 Nos basamos para realizar esta afirmación en la respuesta de Ferrante a la carta del Emperador que le entrega L. Leoni a su regreso a Milán de la corte cesárea: «per leon aretino hebbi anche un'altra lra di V.M. per la quale vidi, come per sua somma modestia et humiltà li piacque rimetter a me l'effetto del disegno de la statua a cavallo Di che con ogni sommisione bacio le mani à V.M. tenendomi di tanto honore che mi fa molto contento, et dato fine, a le altre opere che V.M. desidera imprima, io mi piglierò la cura della detta a Cavallo, percio che io stimo V.M. per la chiarezza della vita et di gesti suoi esser digniss ${ }^{a}$ di eterna memoria quanto altra giamai», Minuta de Ferrante Gonzaga a Carlos V, Vigevano, 10 de enero de 1550, A.S.Pr., Fondo Gonzaga de Guastalla, b.47/7, Registro di coppialettere di Ferrante Gonzaga, s.f. [f.7v.]. La provervial lentitud del escultor para terminar la serie de retratos que deseaba María de Hungría y la posterior caída en desgracia de Gonzaga serían las causas de que la estatua ecuestre no se llevara a cabo.

${ }^{16}$ Plon, E.: op. cit., 1887, p. 380, n. 62. En ella, le pide su intercesión para agilizar el cobro de su pensión y le informa de que ha sufrido, durante mayo y junio, una recaída. También, se refiere a la actividad de su hijo Pompeo en Valladolid gozando del favor de María de Hungría, y de las quejas que tiene de Leone. Para finalizar, suplica al obispo que le comunique cualquier noticia, favorable o desfavorable, sobre su hijo.

${ }^{17}$ El obispo fue paralelamente informado por Ayala, quien le escribe, desde Valladolid, el 14 de mayo de 1558: «Aca se han descubierto algunas heregias luteranas y por la Inquisiçion se prendio al doctor caçaya y a una hera y dos her nos $^{\text {suyos }}$ y a fray domingo de rojas y don $p^{o}$ sarm ${ }^{\prime o}$ hijos del marques de poza y a don luis de rojas su nieto heredero de aquella casa y a su muger de don $p^{\circ}$ y a una hija de la marquesa de alcañizes y otros muchos», B.P., Mss. II/2290, [f. 27]. El 17 de junio se fecha otra nueva carta en la que leemos: «y en lo destos hereges como lleguen algos perlados y theologos que se han llamado se vera lo que dellos se deve hazer y el Empor haze buen fiscal», Ibídem, [f. 46]. El mismo día le escribe el correo mayor, Raimundo de Tassis, sobre el particular: «aqui ha venido Luys quixada por orden del Empr a asistir y dar prisa con grande ynstançia que se haga justicia de los luteranos sin Eçepçion de persona ninguna Pues ha sentido el negoçio con tanta colera y tan de veras como se requiere», Ibídem, [f. 72].

${ }_{18}$ Sobre la figura del cardenal como estadista, continúa siendo fundamental el estudio de VAN DuRME, M.: El cardenal Granvela (1517-1586). Imperio y Revolución bajo Carlos V y Felipe II, Barcelona, 1957.
} 
convincente ante un tribunal inquisitorial, pero demuestra que Granvela estaba dispuesto a pasar por alto, y a convencer al que había sido adalid en la lucha contra el protestantismo ${ }^{19}$ para que también lo hiciese, hasta aquello que atentaba contra sus más firmes creencias si con ello complacía al escultor. Carlos V parece reaccionar ante las peticiones de su ministro, ya que escribe una carta, el 9 de julio ${ }^{20}$, a Juan Vázquez interesándose por el asunto. El secretario debió de presumir que la curiosidad del Emperador se fijaba más en las esculturas que en el propio Pompeo y le contesta, el $14 \mathrm{del}$ mismo mes ${ }^{21}$, haciéndole saber que los bultos están a buen recaudo. Sin embargo, aunque en Bruselas inicia otra insistente campaña, seguramente con idénticos argumentos, con Felipe II, no consigue parejos resultados ${ }^{22}$. El 14 de mayo escribe a Leoni «He hablado más veces al rey sobre las cosas de Pompeo, pero hasta ahora no he podido obtener de su boca que quiera hacer oficio con los inquisidores", comportamiento nada extraño en un rey tan católico. Tras recomendar a Leoni que su hijo se retracte y recordarle lo difícil de solventar el asunto en una corte donde las cuestiones de defensa de la religión eran tan prioritarias ${ }^{23}$, incluso para él mismo, pasa a insinuar que la principal complicación a la hora de convencer a Felipe II de que interceda en favor del hijo del escultor, alegando sus méritos artísticos, reside en el desinterés de éste por la escultura ${ }^{24}$. Las palabras de Granvela, gran conocedor de los gustos artísticos del joven monarca, no pueden ser más claras, a la vez que desalentadoras, para Leone: «en cuanto a aquellas estatuas e imágenes que v.s. ha hecho después del retorno están allí [en España], como sabéis este príncipe se deleita más en la pintura que en la escultura». No obstante, sabedor de detalles como que la inicial reticencia del príncipe, acostumbrado al estilo flamenco, ante la pincelada suelta de Tiziano se transforma en rendida admiración, propone a Leoni una estrategia a seguir para vencer esta indiferencia: "por donde queriéndole inclinar a desear vuestras obras sería necesario tener de blanco oscuro algún retrato que le hiciese venir el deseo de verlas». Tras acuciarle para que el envío

${ }_{19}$ Buena prueba de la opinión de Carlos V sobre estos brotes luteranos surgidos en Valladolid son las cartas en las que aconseja a su hija Juana cómo erradicarlos y castigar a los culpables. Estos documentos han sido publicados por FERNÁNdez Álvarez, M. (ed.): Corpus Documental de Carlos V. IV (1554-1558), Salamanca, 1979, p. 424, DCCCVI.

${ }^{20}$ PLON, E.: op. cit., 1887, pp. 386-87, n. 74. En ella, le pide información sobre: "la causa porque los del consejo de la Inquisición han prendido a Pompeo hijo de Leon sculptor que hizo mi vulto y el del Rey, y vino con ellos acá en la Armada que yo passe ultimamente». MARTí Monsó, J.: Estudios histórico-artísticos relativos principalmente a Valladolid, Madrid, 1898-1901, p. 272, aporta un documento según el cual llegó a Valladolid el 2 de noviembre de 1556.

${ }^{21}$ Plon, E.: op. cit., 1887, pp. 387-88, n. 75: «La prisión de Pompeo el escultor fue por que le acusaron que había dicho çiertas cosas luteranas y por ello le prendio la Inquisiçion y le sacaron en el ultimo auto que se hizo y le penitençiaron en un año que estuviesse en un monasterio y como ha tanto que passo yo tuve por çierto que $V$. M lo sabia. Y los bultos estan a recabdo».

22 Resulta interesante comparar el desinterés de Felipe II en esta ocasión con su preocupación cuando suceda un incidente similar al hijo de Miguel de Coxcie. Esta vez, aunque la intercesión de Granvela ante el Pontífice será decisiva, la iniciativa por obtener el perdón partirá del propio monarca (veáse, CASTÁN, A.: «L'un des peintres de Coxcie aux prises avec l'Inquisition», en Bulletin Acad. Royale de Belgique, $3^{\mathrm{e}}$ Série, T. VII, 1 (1884) y Poullet, E. y Piot, Ch.: Correspondance du cardinal de Granvelle (1565-1586) faisant suite aux Papiers d'Etat du cardinal de Granvelle, Bruselas, 1884, IV, pp. 27 y 34). Granvela se hubo de enfrentar a problemas similares en otros momentos, como ocurrió con Plantino o Jonghelinck.

${ }^{23}$ Parece que Pompeo estuvo de nuevo en prisión al final de sus días, como se deduce de una carta del embajador florentino Tarugi a su patrón, el 15 de febrero de 1607, en la que se trata de las posibilidades de adquirir los manuscritos leonardescos que poseía: "Quel Pompeo Leoni è Architetto del Re, et so che stima infinitamente questi libri; mentre che vivi tengo per impossibile l'ottenerli, ma è già vecchio et è stato carcerato per le cose di Villalunga [conde de Villalonga, don Pedro Franqueza], se venisse a morte, sarà poi facil cosa l'ottenerli, perchè qua non vi sono persone curiose...», GoLDBERG, E.L.: «Artistic relations between the Medici and the Spanish courts, 1587-1621: Part I», en The Burlington Magazine, 1115 (1996), p. 113, nota 62. Agradezco a la Doct. Margarita Estella por haber llamado mi atención sobre esta noticia y por todas sus sugerencias y ayuda a lo largo de la elaboración de este artículo.

${ }^{24}$ El perspicaz escultor ya se había percatado del desinterés del novel rey por su arte, como revela una confidencia que hace, en una carta fechada en Bruselas el 11 de junio de 1556, a Ferrante Gonzaga: «mi doglio della mia sorte che l'Imperadore si sia sepulto [retirado a España junto a María de Hungría]. Né voglio già nè anche restar che confidentemente non dica a v.Ecc ${ }^{a}$ che mi par di veder che gli altri [principalmente, Felipe II] molto poco si dilettino [con la escultura], et no so che si faccino, ne che mondo sia questo...», RonCHINI, op. cit., 1865, p. 37, XXI. 
de este dibujo o boceto de sus creaciones sea lo antes posible, se compromete a hacer todo lo que esté en su mano para mudar la opinión de Felipe II.

Los oficios de Granvela, más en España que en Bruselas, dan el fruto deseado y Pompeo sólo es condenado a pasar un año recluido en un monasterio. Leoni escribe una carta al obispo, el 17 de mayo ${ }^{25}$, en la que le agradece sus desvelos y le comunica que la pena de su hijo ha sido reducida a la mitad y ya ha sido liberado ${ }^{26}$, por lo que puede dedicarse a trabajar. Granvela le contesta el 12 de junio ${ }^{27}$ (Ap. doc. V), con una fuerte reprimenda en materia religiosa, que el escultor debe transmitir a su hijo, y le recomienda que Pompeo, en vez de discutir sobre teología, «sirviendo a Dios, atienda a su arte y labor».

Leone, una vez solventado el espinoso problema de Pompeo, en el que Felipe II no demostró excesiva preocupación, escribe, el 8 de julio, al prelado ${ }^{28}$. Aparte de las noticias que aporta sobre el duque de Sessa, el interés de la carta reside en que contesta a la sugerencia que le hizo Granvela de que hiciese llegar un dibujo de su obra para el Rey con el fin de despertar su interés por sus esculturas. Leoni se disculpa ante Perrenot por no haberlo enviado por dos razones: la lógica desilusión por el poco aprecio que siente Felipe II hacia su arte y el haber estado con fiebre durante los meses de mayo y junio ${ }^{29}$.

Granvela le responde desde Sercamps el 3 de noviembre, felicitándole por la buena acogida que han recibido sus obras por parte del nuevo gobernador de Milán ${ }^{30}$. Éste tomó una medalla de Granvela, quien promete que, una vez regrese a la corte, le enviará otro ejemplar mejor fundido junto a otra medalla de la Emperatriz, también de Leoni. Cuando el obispo de Arrás concluye su misión diplomática de negociar la paz con Francia, salda su deuda con Sessa y le envía las dos medallas desde su residencia estival de Cantecroy, en julio ${ }^{31}$.

En la última carta que escribe el escultor a su protector este año, el 10 de noviembre de $1558^{32}$, hace, de nuevo, referencia a cuestiones pecuniarias y le recuerda que debe enviar las medallas al duque de Sessa. Leoni recibió la carta del 3 de noviembre (Ap. doc. VII), lo que motivó su respuesta del 6 de enero de $1559^{33}$, en la que le comunica que sigue adelante con su trabajo y se pone a su disposición por si el obispo de Arrás desea alguna obra suya. Respecto

\footnotetext{
25 Plon, E.: op. cit., 1887, p. 380, n.63. B.P. , Ms. II/2273, f.86.

${ }^{26}$ Esta noticia de la liberación es un tanto ambigua, pues en la carta de Leoni del 10 de noviembre de 1558 dice a Granvela que diversos asuntos le han impedido "andare a cavare il mio povero figliuolo di quel monasterio dove è confinato».

27 Patanella, el 22 de junio, comunica al obispo que «ho dato anche la sua a ms. leon Aretino», B.P. , Ms.II/2273, f.128.

${ }^{28}$ Plon, E.: op. cit., 1887, p. 381, n.64. B.P. Ms.II/2273, f.159.

29 Ibídem: "Haveria mandato più tosto il dissegno, ma doi cose mi hano sturbato l'animo: l'una, il far tanto pocco conto dela mia professione, o per parlar più coretto, il delettarse pocco dessa; l'altro, d'esser stato tutto maggio et giugno con febre, tenendo anche la mia debil vita memoria de infermità di Gante; ma non mancherò al consiglio di V.S., se ben ce altro che far in coteste bande...».

${ }^{30}$ Leoni también sirve al nuevo gobernador como diseñador de escenarios con alusiones mitológicas para fiestas como el torneo celebrado en el patio del palacio de G.B. Castaldo durante el carnaval de 1559. Para un estudio más pormenorizado de estas celebraciones, nos remitimos a Álvarez-Ossorio Alvariño, A.: «Far cerimonie alla spagnola: El duque de Sessa, gobernador del Estado de Milán (1558-1564)», en Felipe II y el Mediterráneo, Barcelona 23-27 de noviembre de 1998, vol. III La Monarquía y los reinos, Madrid, 1999, p. 457.

${ }^{31}$ «... yo entendí los dias passados por cartas de leon aretino sculptor que v. ex dessearía haver una medalla [guillotinado] de la emperatriz n. $s^{\text {ra }}$ que esta en el cielo y otra mia/ y assi las he hecho hazer y las embio con esta a $v$. ex ${ }^{a}$, Cfr. B.P. , Ms. II/2320, f.94. Minuta de una carta del obispo de Arrás al duque de Sessa, Cantecroy, [s.d., julio, 1559]. Queremos llamar la atención sobre que éstas estarían fundidas en Bruselas, pero no ya por Leoni, sino, posiblemente, por Jonghelink a quien Perrenot utilizaba para acuñar en oro y plata las medallas plúmbeas que conseguía en Italia, como apunta SMOLderem, L.: Jacques Jonghelink. Sculpteur, médailleur, et graveur de sceaux (1530-1606), Louvain-la-Neuve, Départament d'Archeologie et d'Histoire de l'Art, Universitè Catholique de Louvain, 1996, p. 183. Asimismo, el mencionado autor, ha señalado que esta práctica no se limitaba tan sólo a las medallas, y que algunas esculturas broncíneas — pensemos en los relieves ovales de Carlos V de París y Viena - fueron copiadas por el flamenco, dato que se debe tener en cuenta a la hora de las atribuciones.

32 Plon, E.: op. cit., 1887, p. 381, 65. Su ubicación actual: B.P. , Ms.II/2257, f.248.

${ }^{33}$ Ibídem, pp. 381-82, n. 66. B.P., Ms. II/2257, f. 3.
} 
a su hijo, confía en traerlo pronto a Milán, donde esperarán a que Felipe II les encargue alguna escultura, aunque «le esculture gli [a Felipe II] sarano ancora meno a memoria».

Una vez que el emperador ha fallecido, Felipe II decide trasladar la corte a España, de donde no saldrá jamás ${ }^{34}$, por lo que comienza una serie de preparativos que afectaron a Leone Leoni. El Rey, que lleva consigo la mayoría de sus valiosas pinturas reunidas en Bruselas, por primera vez, manifiesta un atisbo de interés por el escultor. Así, escribe desde Bruselas, el 20 de enero de 1559, al duque de Sessa para que se pague la pensión que se debe a Leoni y quede libre con el fin de que "nos baya a servir a España y entender en algunas obras que le havemos encomendado» ${ }^{35}$. Parece que, en esta ocasión, nada ni nadie va a impedir que el escultor cumpla los designios regios, por mucho que le disgustase abandonar Milán, y viaje a España. Leoni escribe varias cartas de las que se deduce que tenía asumido este traslado, pero en las que, también, se vislumbra que se le había atraído con el señuelo de realizar una obra colosal, para la cuál quiere saber si se debe proveer previamente de mármoles de Carrara, bronces y ayudantes. No es difícil de adivinar que el encargo que Leoni imaginaba que iba a recaer sobre él era la sepultura de Carlos V, quien había fallecido recientemente. Este sepulcro colmaría las ansias de gloria del escultor, ya que parte de la fama del césar revertiría sobre él aún en mayor medida que en esculturas anteriores como Carlos $V$ y el Furor, aún sin terminar, y le haría olvidar sinsabores como el frustrado proyecto de la escultura ecuestre que pensaba erigir Ferrante Gonzaga en Milán. Leone sopesaría los beneficios que este viaje podría reportarle y resuelve emprender camino, a pesar de su mala salud, al encuentro de Felipe II. No obstante, pide consejo a su fiel amigo Granvela ${ }^{36}$, cuya respuesta (Ap. doc. VIII), muy sincera, sería descorazonadora para el escultor. El obispo, que parece haber preguntado, como se lo pidió el escultor, al duque de Alba -quien había escrito a Leoni transmitiéndole la voluntad real- sobre cuáles eran los planes concretos de Felipe II respecto a Leoni, averigua que éste sólo le requería para terminar y retocar las esculturas ya comenzadas y que se encontraban en España ${ }^{37}$ : «la [carta] de v.s. del primero del [mes] pasado he recibido y hablado con el Ill ${ }^{\text {mo }}$ duque de Alba sobre aquello que me escrivisteis sobre vuestra ida a España, dice que allí [a la carta que le escribió en la que le comunicaba que debía viajar a España una vez que hubiese llegado el Rey] se remite, y que el motivo era sólo para acabar aquellas cosas que están allí comenzadas, y después que no surgiendo otra cosa, bastará su hijo Pompeo». Es en este momento cuando Granvela, que debía de considerar esta labor como un desdoro para el talento de su amigo, le recomienda, abiertamente y a espaldas de Felipe II, que no abandone Italia ${ }^{38}$. No obstante, el obispo matiza el criticado desinterés de Felipe

\footnotetext{
${ }^{34}$ Salvo la breve estancia en Portugal.

35 Plon, E.: op. cit., 1887, p. 382, n. 67.

${ }^{36}$ En una carta fechada en Milán el 1 de abril, leemos: «Io vado ancora malvolontiere per non esser sano come il solito, ne so quanto mi vi habbia a stare, perciò che la $M^{\text {ta }}$ del Re N.S. solamente ha scritto al S. Duca che mi mandi, onde suplico col cuore che la non voglia mancare di far nota la mia virtù a Sua $M^{\text {ta }}$ (...) et percio prego il detto Signor che accio che si vuol de me la $M^{t a}$ del Re, che se volesse qualque opera grande come sepolcro o statue diverse, che me dia aviso $e$ forma ch'io possa fin che sono qui provedere a Carrara de marmi o de bronzi o de huomini, perciò che colà [en España] non vi si troveran queste cose; che quando fusse per quel tanto che è la già fatto, e bastaria pompeo et a maggior cose», Plon, E.: op. cit., 1887, p. 382, n. 68. B.P., Ms.II/2257, f.175.

${ }^{37}$ En 1567, todavía se encontraban en el puerto de Cartagena «comenzadas, debastadas y puestas bien adelante» varias esculturas de mármol de la familia imperial, como dio a conocer MARTín GonZÁlez, J.J.: «Una nota documental sobre la obra de Leoni», en A.E.A., 91 (1950), pp. 257-58. Para un panorama de la escultura cortesana del reinado de Felipe II, resulta de especial interés el capítulo III de su libro El escultor en Palacio. Viaje a través de la escultura de los Austrias, Madrid, 1991.

${ }^{38}$ Ésta no es la única ocasión en que Granvela se comporta de esta manera. Cuando Fulvio Orsini, el bibliotecario de los Farnesio, decide, en 1581, legar su magnífica librería y las antigüedades que la decoraban a Felipe II para que engrosase los fondos de la Laurentina, Granvela, que actuaba como intermediario, disuade a su amigo romano al juzgar que estos tesoros no serán suficientemente apreciados en España, como nos informa NolHAC, P. de: Lettere inedite del cardinale de Granvelle a Fulvio Orsini e al cardinale Sirletto, Roma, 1884, pp. 254-56.
} 
II por la escultura reduciéndolo a un fenómeno puntual y que se podrá solventar en un futuro. Para el prelado, la explicación está, sobre todo, en la política artística que ha decidido acometer el Rey a su regreso, enfocada a obras arquitectónicas, en cuya decoración tenían cabida las pinturas que ya poseía, pero que, por el momento, no se había planteado su ornamentación con esculturas. Una vez que estas empresas arquitectónicas que ocupan a Felipe II estén concluidas, si decide, como presumiblemente lo hará, dotarlas de esculturas y requiere los servicios de Leoni, Granvela le aconseja que no ponga ninguna excusa para obedecerle, pues nada puede beneficiar más al escultor que trabajar al servicio del soberano más poderoso del momento. Como en otras ocasiones, Perrenot se despide ofreciendo al escultor su intercesión ante el monarca para modificar su opinión: «me parece como amigo suyo que soy que no sería necesario que v.s. vaya, yo veo a nuestro rey preocuparse poco por ahora de la escultura y estar su ánimo más inclinado a la pintura y arquitectura, las cuales quizá podría llegar ocasión queriendo su magestad hacer algunos grandes edificios y meter estatuas, o medallas que hubieran todavía un día necesidad de la obra de v.s., y en tal caso, le aconsejaría soportar cualquier incomodidad para no faltar de servir a un tal príncipe y patrón como el nuestro, pero por ahora no siendo tan necesaria su presencia alli, me parece que se debe estar quieto, o ud. decidirá aquello que juzgue mejor». Aunque Felipe II se ocupa en estos primeros años de reformar algunas residencias en los alrededores de Madrid, parece que el gran edificio al que alude el cardenal, y que ya estaría en mente del Rey, sea El Escorial, cuya principal función era la de Panteón de la Dinastía.

Es en este momento cuando tiene lugar un nuevo episodio violento en la vida de Leoni. Orazio Vezellio, hijo de Tiziano, hasta el momento amigo del escultor, visita Milán hospedándose en casa de Leoni, en la que es brutalmente agredido por éste con el fin de apoderarse de la pensión del veneciano. Tiziano escribe una exaltada carta a Felipe II, el 12 de julio de $1559^{39}$, poniéndole al corriente del suceso y clamando justicia. Aunque, desgraciadamente, no hemos encontrado el documento, Leone Leoni escribió, a su vez, a su protector en la corte el 18 de julio, seguramente, dándole su versión de lo acaecido ${ }^{40}$. Lo que sí que se conserva es la respuesta de Granvela, fechada el 30 de julio (Ap. doc. IX): «me ha disgustado bastante el embrollo que os ha sucedido en casa, no he oido hasta ahora palabra ninguna en esta corte. Sin embargo, agradezco ser advertido de las justificaciones y excusas de v.s., para que, si fuese necesario, pueda responder por ud. como convenga». De nuevo, encontramos el incondicional apoyo de Granvela a Leoni, incluso en los momentos más difíciles y comprometidos. El que en la siguiente carta de Felipe II a Tiziano no se haga la más mínima mención al asunto y la insistencia del pintor en sucesivas cartas, junto a las que envía cuadros que serían muy estimados por el Rey, para que incoe un proceso judicial en Milán para castigar al aretino, parecen dar a entender que, o bien las excusas del escultor resultaban convincentes, o bien que los oficios a favor de Leoni que Granvela prometió hacer ante el Rey dieron los resultados deseados. Tiziano, ya en 1560, no se limita a recordar a Felipe II la trayectoria criminal de Leoni, sino que llega a atacar su arte, alegando que fue una inmerecida suerte que Carlos V le acogiese como escultor cesáreo y le permitiese retratar en esculturas de gran tamaño habiendo en Italia «docenas de escultores que

\footnotetext{
39 A.G.S., Estado, leg.1323, f.286. Fue dada a conocer por CavalcaSelle, G.B. y Crowe, J.A.: Tiziano, la sua vita, $i$ suoi tempi, Florencia, 1877-78, II, pp. 238-41. El que Felipe II no responda y que nada se comente en la corte sobre el altercado puede deberse a la multitud de asuntos políticos que debe resolver el Rey antes de su partida, al lado de los cuáles la disputa entre los dos artistas sería una menudencia.

${ }^{40}$ La versión más completa del suceso nos la proporciona CADORIN, G.: Dello amore ai Veneziani di Tiziano Vezellio, Venecia, 1835, pp. 48-53. También, es recogido el proceso por CASATI, C.: Leone Leoni d'Arezzo scultore e Giovanni Paolo Lomazzo pittore milanese, Milán, 1884, pp. 29-33. Cuando es conducido ante los tribunales, el escultor alega los escarceos de Orazio con una sirvienta de su casa.
} 
saben más que él» ${ }^{41}$. Estas últimas palabras hacen pensar que lo que subyace en el enfrentamiento es una rivalidad artística, pues cuando se interroga al joven Orazio sobre cuál considera el móvil de la agresión, éste contesta que la envidia del escultor por su éxito en Milán y los numerosos encargos de retratos que había recibido. Ya, años atrás, ambos habían realizado famosos alegatos en defensa de la escultura y la pintura dentro de uno de los debates teóricos más candentes durante el Renacimiento como era el del paragone ${ }^{42}$. En tiempos de Carlos V, los dos gozaban de casi idéntico favor por parte de la Casa de Austria pero, una vez muertos el Emperador y su hermana María, la balanza se desequilibra claramente en favor de Tiziano, al que Felipe II seguirá encargando cuadros al ritmo de antaño ${ }^{43}$, mientras que parece no necesitar los servicios de Leoni para ninguna empresa de importancia. Ésto último y el aprecio que siente el divino Miguel Ángel, cuyas críticas a la Dánae de Capodimonte tizianesca no fueron precisamente elogiosas, por el escultor aretino, a quien recomienda ${ }^{44}$ al Papa para que ejecute el sepulcro de su hermano, en cuyo proyecto le ayudaría, pueden ser el desencadenante de la agresión de Leoni ${ }^{45} \mathrm{y}$ de las duras críticas de Tiziano el año siguiente. El incidente parece arreglarse con una compensación económica del aretino al joven pintor que, en 1562 y ya en Venecia, pide permiso para llevar armas por miedo a volver a ser atacado.

La decisión que toma Leoni respecto a su porvenir es la de seguir los sabios consejos de su mentor y marchar a Roma, donde le encontramos en 1560. Sin embargo, Leoni no se aviene a claudicar por lo que ofrece al monarca una proposición tan tentadora que, al menos a su juicio, era casi imposible que se resistiese ${ }^{46}$. El 22 de junio de $1560^{47}$ escribe a Granvela comunicándole que se encuentra en la Ciudad Eterna al servicio del Papa, Pío IV, al que ha efigiado en una medalla y quien le ha encargado la realización del sepulcro de su hermano, el marqués de Marignano, en el duomo milanés. Aunque el diseño de esta tumba parietal es del aretino, Miguel Angel le ayudaría y, aprovechando la feliz coincidencia, sugiere a Granvela que si Felipe II se

${ }^{41}$ Carta de Tiziano a Felipe II, Venecia, 24 de marzo de 1560 (A.G.S., Estado, Venecia, leg.1324, f.224) dada a conocer por Cavalcaselle, G.B. y Crowe, J.A.: op. cit., 1877-78, II, pp. 275-6. A este respecto, también resulta de interés la carta del pintor al Rey, fechada en Venecia el 22 de marzo de 1559 (A.G.S., Estado, leg. 1323, f.287), Ibídem, pp. $245-48$.

${ }^{42}$ Los argumentos esgrimidos por Leoni en defensa de su arte serían su raigambre clásica, su mayor perdurabilidad y la posibilidad de ser contemplada desde diferentes puntos de vista, igualmente privilegiados, como se desprende de la famosa carta que escribe a Ferrante Gonzaga y que dió a conocer CAMPORI, G.: Gli artisti italiani e stranieri negli stati estensi, Módena, 1855 y que volvió a reproducir Ronchini, A.: op. cit., 1865, pp. 24-25, IV. Por su parte, Tiziano no se queda a la zaga y, además de emplear topoi clásicos como la amistad entre Apeles y Alejandro, la primera pareja de sus Poesías para el príncipe Felipe -Dánae y Venus y Adonis, ambas en el Museo del Prado- es explicada al joven como el estudio de una misma figura femenina desnuda para ser vista por delante y por detrás, lo que fue interpretado como un alegato en defensa de su arte por Rosand, D.: «Ut pictor poeta: Meaning in Titian's Poesie», en New Literary History, 3 (1971-72), pp. 527546.

${ }^{43}$ Sobre este tema, veáse Checa Cremades, F.: Tiziano y la Monarquía Hispánica, Madrid, 1994 y la introducción a la nueva recopilación de la correspondencia de MAncini, M.: Tiziano e le corti d'Asburgo nei documenti degli archivi spagnoli, Venecia, 1998.

${ }^{44}$ Esta es la versión que nos ofrece un amigo de Leoni que quizá no fuese todo lo imparcial que debiera, MaLASPINI, C.: Ducento Novele, Venecia, 1609, I, nov. LXXXV, f. 228v. Según Malaspini, Pío IV encarga el sepulcro de su hermano a Miguel Angel pero éste, encontrándose viejo y no queriendo abandonar Roma, recomienda a Leoni al Papa, quien llama al escultor a Roma. Sin embargo, todo apunta que la precipitada marcha a Roma sea un subterfugio para alejarse lo más posible del altercado con el hijo de Tiziano. Ésta coge por sorpresa al propio obispo de Arrás quien declara que no le ha pedido la medalla del Pontífice porque «ni siquiera sabía que estuviese en Roma» (Ap. doc. IX).

${ }^{45}$ Otro asunto pendiente entre Tiziano y Leoni se remonta a la estancia del escultor en Venecia acompañado de su ayudante Martino que se negó, presumiblemente aconsejado por el pintor, a abandonar la ciudad por lo que Leoni envió un asesino a sueldo a darle muerte. Sobre este tema, veáse Plon, E., op. cit., 1887, p. 30.

${ }^{46}$ En el último parrafo de la famosa carta escrita a Granvela desde Roma, el 22 de junio de 1560 (Plon, E.: op. cit., 1887 , p. 383 , n. 69), el escultor estima que Felipe II no rechazará su idea dada su admiración hacia Miguel Ángel reflejada en una carta que escribió el Rey a su embajador en Roma, Francisco de Vargas, y que éste mostró a Leoni, donde se refería al escultor florentino: «Sua Maestà non mancherà di cio, ch'io ne son certo, per cio che non ha molto che l'imbasciator Vargas ne haveva lettere dove ci era un capitolo per esso Michelagnolo, tutto amorevole e profitevole».

${ }^{47}$ Plon, E.: op. cit., 1887, p. 383, n. 69. B.P., Ms. II/2319, ff. 84-85. 
lo pidiese al florentino, éste podría diseñar el modelo para la tumba imperial ${ }^{48}$. Granvela acoge con gran entusiasmo la sugerencia de Leoni, que ha trabado amistad con el anciano Miguel Angel, y se dispone a escribir a la corte española para ver cómo es recibida la idea. El 28 de julio envía la famosa misiva ${ }^{49}$ al secretario del Rey, Gonzalo Pérez, al que le unían estrechos lazos de amistad, apoyando el proyecto, que llevaría a cabo Leoni cuando el Rey estimase oportuno, si Felipe II aceptaba. Al día siguiente, el 29 de julio, se lo comunica a Leoni (Ap. doc. X), al que felicita por haber conseguido el favor del Papa, justamente merecido: «he ya escrito a España, para que se entienda la voluntad de su Mata sobre aquello que apuntáis de querer obrar con Miguel Ángel, que hiciese algún diseño para la sepultura de nuestro invictísimo emperador Carlos de fe[liz] me[moria], pero que sería necesario que su Ma ${ }^{\text {ta }}$ le escribiese alguna palabra, o al menos a v.s. algo que le pudiese mostrar, veremos qué responderán, que verdaderamente a mí me parecería digno, que de un hombre tal se procurase, con todo esfuerzo, conseguir una cosa semejante». Granvela, apasionado de las medallas, al enterarse que el aretino ha fundido la del pontífice, cuyo retrato sobre cualquier soporte llevaba tiempo buscando, le pide un ejemplar en plomo para, como era habitual en él, sacar copias en oro y plata ${ }^{50}$.

La carta que había escrito Granvela al culto secretario del Rey, ofreciéndole la posibilidad de que el pintor y escultor florentino realice alguna obra para Felipe II, estaba hábilmente calculada. Primeramente, se exagera el aprecio del que goza el escultor aretino en la corte papal y las renuncias que debe hacer para seguir fiel al servicio del Rey. También, para hacer a éste decidirse pronto en favor de una propuesta tan ventajosa y que podría tomar «cuando su Majestad quisiese», le acucia para que responda en breve por el poco tiempo que queda de estancia romana a Leoni ${ }^{51}$ y la avanzada edad de Miguel Angel, a la que añade cinco años. Por último, conocida la predilección del Rey por la pintura, le ensalza las excelencias del florentino en este campo ${ }^{52}$ con el fin de despertar su atención.

Sin embargo, todas estas molestias resultan infructuosas, pues la idea es desechada. Desde Toledo, donde residía la corte, el 5 de septiembre, Gónzalo Pérez contesta a Granvela y, en relación a sus propuestas ${ }^{53}$, dice: «En lo de la sepultura del Emper he d[ic]ho a su mag ${ }^{d}$ lo que v.s. me escribe por el aviso de Leon [Leoni]ly lo mismo le habia scripto el duq[ue] de alva por aviso del car'[denal] Montepulchano [Montepulciano]/ y su $m^{d}$ me ha mandado responderle que no está en hazer semejante edifizio por ser cosa contra la voluntad y orden de su padre y muy agena de su condición/ tanto que el Emp[erado]r dio la orden que quería que se

\footnotetext{
${ }^{48}$ Miguel Angel no es el único candidato a realizar el sepulcro de Carlos V, pues Guglielmo della Porta, il fratte del piombo, envió también su proyecto, que Gonzalo Pérez archiva junto a la propuesta de Granvela, como ha señalado MARíAs, F.: «La iglesia de El Escorial: de templo a basílica», en Felipe II y el arte de su tiempo, Debates sobre Arte. Fundación Argentaria, 8, Madrid, 1998, pp. 29-53. También se publican en este mismo volumen otros estudios de interés para el tema que tratamos: Bustamante, A.: «Las tumbas reales de El Escorial», pp. 55-78, y Rodríguez G. De Ceballos, A.: «Felipe II y la Escultura: el retrato de busto, la medalla y la escultura decorativa», pp. 425-40.

${ }^{49}$ Plon, E.: op. cit., 1887, pp. 383-84, n. 70. Antes de por él, fue dada a conocer, en francés, por GaCHARD, L.P. : Correspondance de Philippe II sur les affaires des Pays-Bas, Bruselas, 1848, I, p. 191 y, en español, por OcHOA, E. de (ed.): Epistolario español. Colección de cartas de españoles ilustres antiguos y modernos, LXII, Madrid, 1870, p. 25, IX. La minuta de esta carta se conserva en la B.P. , Ms. II/2305, f.121.

${ }^{50}$ La medalla se la envía Leoni desde Milán, junto a la de Miguel Ángel, la del marqués de Pescara y la del duque de Sessa, el 15 de marzo de 1561 (Plon, E.: op. cit., 1887, pp. 384-85, n.71. B.P. , Ms.II/ 2275, f.126). En su anverso, aparecía el busto del Pontífice con la leyenda: PIVS.IIII.PON.OPT.MAX.ET.ANNO.I.PON.MDLX y, en el reverso, una gallina cobijando, bajo sus alas, a sus polluelos ante un edificio en llamas con la inscripción: DESIDERIO. DESIDERAMVS.

${ }_{51}$ Ésta se prolongará hasta primeros de octubre, ya que el 14 de este mes le encontramos en Florencia rumbo a Milán.

52 Éstas no pasarían inadvertidas al rey, ya que un año antes intercede en su favor alegando "ser el Michael Angelo de tan raro ingenio y tan exçelente en su arte...», como ha señalado MARIAS, F.: «Felipe II y los artistas», en El arte en las cortes de Carlos V y Felipe II. IX Jornadas de Arte del Departamento de Historia del Arte «Diego Velázquez» del C.S.I.C., Madrid, 1999, p. 244.

${ }^{53}$ Esta carta se custodia en la B.P., Ms. II/2291, f. 229v. También se refiere a un memorial que dio a Granvela un ingeniero para mostrar al Rey, sobre lo que contesta que Bartholomé Campi hace cosas semejantes.
} 
tuviesse en ello y es tan agena dessas gentilidades que no está puesto en ello y assi v.s. le puede desengañar». No existe duda alguna de que a lo que se refiere Gonzalo Pérez es al codicilo testamentario que redactó Carlos $V$ en Yuste poco antes de morir y que su hijo pensaba respetar. En él, aunque dejaba vía libre al Rey para que le enterrase donde estimase oportuno, determina que, si se le da sepultura definitiva en Yuste, se labre un retablo en alabastro inspirado en El Juicio Final de Tiziano y se le efigie, junto con la Emperatriz, en actitud orante ante un tabernáculo, que se situaría a la derecha del altar, descalzos y envueltos en una sábana, a modo de sudario, tal y como aparecían en el cuadro ${ }^{54}$. Esta idea de adoración perpetua ante el Santísimo Sacramento estaría inspirada en las vidrieras de la catedral de Santa Gúdula de Bruselas y es la que subyace, en última instancia, en los definitivos cenotafios escurialenses ${ }^{55}$.

Aunque en la carta de Granvela no se hace referencia a ningún sepulcro concreto de Miguel Ángel, como el de los Medici en Florencia o el de Julio II que ya eran muy famosos, sí que se califica al proyecto, y en dos ocasiones, de suntuoso, algo en absoluto acorde con los deseos del Emperador, pero no concluyente para su total rechazo. Todo apunta a que la negativa y la acusación de "gentilidades» ${ }^{56}$ se deba a la propuesta que le llegó al Rey a través del duque de Sessa ${ }^{57}$ o del cardenal Montepulciano y del duque de Alba ${ }^{58}$ a la que alude Gonzalo

${ }^{54}$ SAndoval, Fr. P. de: Historia de la vida y hechos del Emperador Carlos V. Máximo, fortísimo, Rey Católico de España y de las Indias, Islas y tierra firme del mar Océano, ed. C. Seco Serrano, Madrid, 1956, III, pp. 533-561. La parte del codicilo, del 9 de septiembre de 1558, a la que nos referimos es: "Item, ordeno y es mi voluntad, que si mi enterramiento hubiere de ser en este dicho monasterio, se haga en el altar mayor de la iglesia del un retablo de alabastro y medio relieve del tamaño que pareciere al rey y a mis testamentarios, y conforme a las pinturas de una figura que está mia, que es el Juicio Final de Tiziano, que está en poder de Juan Martín Estur, que sirve en el oficio de mi guardajoyas, añadiendo o quitando de aquello lo que vieren mas convenir. E asimismo se haga una custodia de alabastro o mármol, conforme a lo que fuere el dicho retablo, a la mano derecha del altar, que para subir a ella haya cuatro gradas para adonde esté el Santísimo Sacramento, y que a los lados de ella se ponga el busto de la Emperatriz y el mío, que estemos de rodillas, con las cabezas descubiertas y los pies descalzos, cubiertos los dos cuerpos como con sendas sábanas del mismo relieve, con las manos juntas, como Luis quijada, mi mayordomo y F. Juan Regla, mi confesor, con quien lo he comunicado, lo tienen entendido de mí. Y en el caso que mi enterramiento no haya de ser ni sea en este dicho monasterio, es mi voluntad que en lugar de la dicha custodia y retablo se haga un retablo de pincel de la manera que pareciere al rey mi hijo y a mis testamentarios, y así lo ruego y encargo».

${ }_{55}$ El codicilo es de nuevo tenido en cuenta años después, como apuntó CHECA, F.: «(Plus) Ultra omnis solisque vias. La imagen de Carlos V en el reinado de Felipe II», en Cuadernos de Arte e Iconografía (F.U.E), 1 (1988), p. 79, nota 26. Sobre su influencia en los definitivos cenotafios, veáse MulCaHy, R.M.: "A la mayor gloria de Dios y el Rey». La decoración de la Real Basílica del Monasterio de El Escorial, Madrid, 1992, caps. 3 y 7. Acerca de la posterior ejecución de los grupos orantes, nos remitimos a los artículos de Bustamante GARcía, A.: «Las estatuas de bronce del Escorial. Datos para su historia (I), (II) y (III)», en Anuario del Departamento de Historia y Teoría del Arte (U.A.M.), V (1993), pp. 41-57 (I); VI (1994), pp. 159-77 (II); VII-VIII (1995-96), pp. 69-86 (III), todos ellos con bibliografía precedente.

${ }^{56}$ Carlos V, antes de esta nueva decisión, pensaba recibir sepultura en la rotonda de la catedral granadina, donde quizá hubiese tenido mayor cabida el diseño miguelangelesco.

${ }^{57}$ En la carta que escribió Leoni a Granvela, desde Roma, el 22 de junio (Plon, E.: op. cit., 1887, p. 383, n.69), le informa de que: «...ho scritto al S. Duca di Sessa, al quale, senza freno o sperone, ho fornito più che habbia giamai fatto a Principe, confacendosi col mio humor stravagante, che faccia sapere a Sua Catolica Maestà come io ho di vena quel divino huomo di Michelagnolo, et che se si cava una lettera di Sua Maestà che mi pervenghi ne le mani a me, ma diretta a lui, mi da il cuore di fargli fare un disegno et modello de la sepoltura de la Felice Maestà del Imperadore, et se non si gli vuol scrivere a lui, diasi licenza a me in nome di Sua Maestà, et lascisi far a me. Ma sapendo quanto V.S.Ill ${ }^{\text {ma }}$ è stata calda sempre nelle mie bisogni, et defidandomi d'ogni persona, eccetto che di V.S., sono forzato a suplicarla che non lasci perder questa occasione grande che si faccia questo disegno per mano di questo divin huomo, il quale hora per la fama di tanto Re gli si mostra affecionato. Si che V.S. mi faccia questa gracia in la maniera che piu li piacerà, o scriver al Ill ${ }^{\text {mo }}$ di Sessa, che ne parli con Sua Maestà, over cavarne una lettera, come gli parerà a lei, che io dal mio conto farò cio che desidera, havendo ogni favore et ogni domesticheza da lui». Como hemos visto, Granvela decide escribir directamente al secretario del Rey en vez de al gobernador de Milán al considerar esta vía más eficaz. Posiblemente, el duque de Sessa comunicaría verbalmente la propuesta de Leoni al Rey, pues, el 23 de junio de 1560, envía, desde Toledo, una carta a Granvela en la que le hace saber que ha informado de todas las nuevas italianas a Felipe II (B.P. , Ms.II/2319, f.94).

${ }^{58}$ Hemos buscado alguna referencia a la carta que escribió el duque de Alba al Rey o de la que pudo escribir Montepulciano al Duque en el Archivo de la Casa de Alba con resultado negativo. VASARI, G.: Le vite di piu eccelenti architetti, pittori et scultori italiani (1568), ed. G. Milanesi, Florencia, 1878-81, VII, p. 538, nos informa de que el duque encarga tres bustos a Leoni: el suyo, el de Carlos V y el de Felipe II. Un recibo del tesorero del duque, fechado en Augsburgo el 4 de 
Pérez. Giovanni Ricci de Montepulciano ${ }^{59}$ mantenía estrechos contactos con los ambientes españoles desde sus viajes a la Península Ibérica y conocía tanto a Felipe II como a altos personajes de la corte. Posiblemente por este motivo fue elegido por Leoni como tercer cauce para hacer llegar su sugerencia a Felipe $\mathrm{II}^{60}$. Por desgracia, no sabemos si en la carta escrita por Alba se hacían referencias directas o al proyecto de Leoni, que se recoge en un contrato del 12 de septiembre, pero que se vendría madurando desde tiempo atrás ${ }^{61}$, o a los sepulcros de Miguel Ángel que, si se confrontan con las disposiciones testamentarias de Carlos V, merecen justificadamente la calificación de «gentilidades» que reciben en la corte española.

Otra posible explicación para que se tilden de paganizantes ${ }^{62}$ y del tajante rechazo podría ser que, al haber Gonzalo Pérez archivado la propuesta de Granvela junto a la del frate del piombo ${ }^{63}$, que era la reelaboración de un proyecto anterior, de hacia 1550, para un monumento ecuestre que pensaba levantar Julio III en honor del Emperador en Roma ${ }^{64}$, fuesen mostrados juntos al Rey. La traza de G. della Porta, una imagen más efectiva que la carta de Granvela y que distaba tanto de las últimas disposiciones testamentarias del Emperador, pudo ser tomada por Felipe II como un resumen de las dos proposiciones romanas que fueron desestimadas conjuntamente. Significativamente, es en este año de 1560, cuando Leoni se encontraba aún en Roma, el momento en que surgió la idea de regalar a Felipe II una serie de esculturas antiguas y otras obras de arte para ornamentar sus jardines y palacios ${ }^{65}$. Aunque la iniciativa parte de Pío IV, gran aficionado a las antigüedades, diversos cardenales, entre los que se encontraba

enero de 1558 (Archivo de los Duques de Alba, caja 222-7-26), avala esta relación entre el duque y el escultor y lo ofrece F. Bouza en la ficha de catálogo correspondiente a un retrato de Carlos Manuel de Saboya, atribuido al aretino, en el cat. exp. Felipe II. Un príncipe del Renacimiento, M. del Prado, 1998-99, p. 414, 104.

59 Una aproximación a este cardenal es el estudio de Deswarte-Rosa, S.: «Le cardinal Giovanni Ricci de Montepulciano», en La Villa Médicis, Académie de France et l'Ecole Française de Roma, II, 1992, pp. 111-169 y su artículo «Le cardinal Ricci et Philippe II: cadeaux d'oeuvres d'art et envoi d'artistes», en Revue de l'Art, 88 (1990), pp. 52-63.

60 Montepulciano también se encontraba muy relacionado con Guglielmo della Porta, el escultor que presentó otro proyecto para la escultura imperial y que también trabajó para el cardenal.

61 Sobre este sepulcro parietal, veáse SpIRITI, A.: «Leone Leoni nel Duomo di Milano: il mausoleo del Medeghino», en Convegno Leone Leoni tra Lombardia e Spagna (Menaggio, 25-26 de septiembre de 1993), Milán, 1994, pp. 11-20. En él aparecía el marqués de Marignano como un héroe clásico flanqueado de dos alegorías femeninas de la Milizia y de la Paz.

62 En el artículo de M. MoRÁN, 1994, se apunta que el rechazo de la escultura ecuestre por parte del Emperador pudo deberse a reminiscencias de su educación erasmista (p. 19) y, asimismo, se recoge la opinión, si bien de finales del siglo, cuando los preceptos contrarreformistas están muy asentados, de Villalta respecto al rechazo de la escultura por parte de la familia real (p. 21).

${ }^{63}$ La anotación de Gonzalo Pérez resumiendo el contenido de la carta es: «Lo de la sepultura del Emperador para que haga el designo Miguel Angel-Lo que ofrece el fraile del plomo sobresto mismo». Curiosamente, esta no es la única ocasión que L. Leoni y G. della Porta coinciden en un encargo. En una carta que escribe G. della Porta al cardenal Alessandro Farnesio, leemos: «Il primo anno di nostro $S^{\text {or }}$ papa Pio 4 [1559] fu ricercato che io volese fare la sepoltura del marchese [de Marignano] ms. Michele Angelo in sema con il resto de larte non ha voluto", GramberG, W.: Die Düsseldorfer Skizzenbücher des Guglielmo della Porta, 3 vol., Berlín, 1964, p. 120, 225.

${ }^{64}$ En la iniciativa también estaban involucrados el embajador español en Roma, Diego Hurtado de Mendoza, que legó su magnífica colección a Felipe II (sus esculturas clásicas, en su mayoría conservadas en el M. del Prado, son enumeradas en Foulché-Delbosch, R.: «Un point contesté de la vie de don Diego Hurtado de Mendoza», en Revue hispanique, II (1895), pp. 290-303) y el cardenal Maffei. El monumento se componía de un templete con los catorce misterios de la pasión fundidos de medio relieve y la escultura ecuestre propiamente dicha, inspirada en la de Marco Aurelio, con alegorías femeninas de cuatro provincias - Italia, Alemania, Sicilia y África- y vencidos. Nos podemos hacer mejor una idea de la propuesta de hacia 1559-60 por las dos cartas reproducidas por GRAMBERG, W.: op. cit., 1964, pp. 118-120, 223 y 224 y $\mathrm{n}^{\mathrm{os}}$ de cat. 134 y 141. Este proyecto ha sido analizado recientemente por MARÍAs, F.: op. cit., 1998, pp. 30-32, a quien seguimos en este punto.

${ }^{65}$ Ya el príncipe Felipe, de apenas trece años de edad, recibió una escogida colección de monedas antiguas de emperadores romanos enviada por el obispo de Borgo de S. Sepulcro a través del embajador español en Roma. Con ellas se buscaría despertar el interés del joven por la Antigüedad, que serviría de modelo en su educación, al igual que las esculturas clásicas que promete enviarle próximamente: «Per una di vra Altezza scritta allo Ill seg $^{\text {or }}$ Marchese d'Aguilara ambassiatore di S.M ${ }^{\text {tà }}$ ho visto no'esser' despiaciuto a V.Altezza un minimo dono ch'io li feci per inviarli certe puoche medaglie il che me ha datto animo a prepararli cose antiche rarissime, non solo di Medaglie ma di Statue, De le quali son[o] certo che ne havera satisfattione grandiss ${ }^{a}$...», Obispo Archinto al príncipe Felipe, Roma, 21 de junio de 1540, A.G.S., Estado, Roma, leg. 869, 72 y 73. 
Montepulciano, se adhieren y aportan algunas obras. El conjunto es descrito en una carta, fechada en Roma el 19 de octubre, que escribe el maestre de postas de S.M. en Roma, Juan Antonio de Tassis, al obispo de Arrás ${ }^{66} \mathrm{y}$, por otras referencias, sabemos que la escultura del general cartaginés, junto a una de Sócrates y otra de César, eran un obsequio de Montepulciano ${ }^{67}$. Sin embargo, parece que la visita a Roma del Gran Duque de Toscana, Cosimo I, para rendir pleitesía al Pontífice, hace que cambien los planes de Pío IV y que el presente destinado a Felipe II terminase aumentando la colección de su pariente ${ }^{68}$. Montepulciano no estaría en desacuerdo con la nueva decisión del Papa, dada su ligazón con los Medici resaltada por Deswarte-Rosa, pero, consciente de la utilidad de las obras de arte con fines diplomáticos, enviará, el año siguiente ${ }^{69}$, una nueva serie de esculturas, esta vez copias modernas, que sí llegarán

${ }^{66}$ «S. $S^{t a}$ fa imbarcare in queste galere [hacia España] le cose che manda a presentare a S.M ${ }^{t a}$ che sono tutte cose miracolose fra le quali vi sono parecchie teste antiche; vi e quella d'Hannibale Cartaginese che era sola in Roma. un bell ${ }^{\text {mo }}$ Oratorio; quattro colonne di marmo mischio come gioie, con una tavola di marmo mischio anch'egli ecc ${ }^{\text {mo }}$, un altra d'ebano, col partimto di pietre singolarisso, un organo rariss ${ }^{\circ}$ etraniss ${ }^{\circ}$ un tabernacolo di metallo fuor di modo con altre cose pretiose», B.P. , Ms. II/ 2274, f. 205. En otra carta posterior, fechada en Roma el 12 de noviembre de 1560, se lee: «S. Sta mandera con le Galere di Spagna il presente che ha ordinato per la Mta Cathca», B.P., Ms. II/2249, f. 40. Este envío también es descrito por el conde de Arco en una carta fechada en Roma, el 12 de octubre de 1560: «...Fra quindici giorni partirà [Anibale da Ems] et portarà seco presenti al Re catolico una spada, una tavola, un organo et un oratorio; alla regina manda ancora il papa una croce, alla principessa di Portugallo, alla duchessa d'Alba, alla moglie di Rui Gomez diverse altre cose», en Jahrbuch Kunsthistorischen Sammlungen (J.K.S.), 11 (1890), Reg. 6506.

${ }^{67}$ En el aviso de Roma del 12 de octubre de 1560, conservado en la Biblioteca Vaticana (BAV), Urb. Lat. 1039, f.209, citado por Deswarte-Rosa, S.: op. cit., 1990, p. 60, nota 7, se nos informa sobre las esculturas: "Il cardinale Carpi ha portato a N.S' una testa antiqua d'Alessandro magno et il cardinale Montepulciano tre altre una d'Hannibale, di Socrate et di Cesare, le quali si dice S. ${ }^{t a}$ manda al Re $P h^{\circ}{ }$. Sobre el posible envío de una escultura de Venus a Felipe II, veáse su artículo de 1992, p. 158, nota 204.

68 K.F. Rudolf, en su artículo «Antiquitates ad ornatum hortorum spectantes (Coleccionismo, Antigüedad clásica y jardín durante el siglo XVI en las cortes de Viena y Praga)», en el cat. exp. Adán y Eva en Aranjuez..., 1992, p. 24, nota 47, hace referencia a una carta que escribe Galeazzo Cusano a Maximiliano II desde Roma, el 4 de enero de 1561, en la que le informa del cambio de destinatario de las antigüedades: «A Romani non è sodisfatto punto, che sua eccelenza [Cosimo I] ha portato via di Roma una gran quantità di statue di marmo et molt'altre antichaglie delle più belle che vi fussero, et il papa gli ha donate tutte quelle haveve racolte per mandar alla maestà catolica et di più gli ha dato un Mercurio che era in Belvedere di marmoro et un gran pillo di serpentino, cose rarissime che vagliono un tesoro", en JKS, 11 (1890), Reg.6510. Ésta no es la única ocasión en que la pasión de los Medici por las antigüedades hace que revierta en ellos un presente destinado a Felipe II, algo que no hubiese sucedido si el monarca hispano se hubiera sentido atraído por éstas, dado el abismo que separaba a ambos desde un punto de vista político. Así, una serie de camafeos de los Doce Césares, preparada como regalo para Felipe II, es comprada, en 1587, por Ferdinando de Medici por 60 escudos a través de sus agentes en Roma, Giovanni Antonio y Domenico dei Cammei, como nos informa CaSARosa GuadaGni, M.: «Le gemme dei Medici nel quattrocento e nel cinquecento», en Tesori dalle collezioni medicee, Florencia, 1997, p. 90. Por otra parte, MoRÁN, M.: op. cit., 1992, p. 46, nota 28, recuerda cómo el Duque de Villahermosa poseía en su colección una estatua de Julio César copiada por G. Battista Bonanone «de una antigua que Pio quarto embió al Rey nuestro señor». Otro testimonio que contradice a Cusano lo ofrece Venturini da Fabriano quien, en su descripción del Alcázar madrileño, se refiere a esculturas donadas a Felipe II por Pío IV: «presso le cucine in un altra guardarobba oltre molte cose diverse di bronzo, di marmo, di stucco si viddero quattro teste antiche di marmo di Annibale, di Pirro, di Settimio et di Adriano, donate già di Pio IIII (...) a Su Maestà Cattolica», en Del viaggio del Cardinale Alessandrino legato alli serenissimi Re di Francia, Spagna et Portogallo, B.A.V., Barb. Lat. 5216, f.131, citado por RudolF, K.: «Die Kunstbestrebungen Kaiser Maximilians im Spannungsfeld zwischen Madrid um Wien», en JKS, 91(1995), p. 207, nota 365. En el inventario levantado a la muerte de Felipe II, publicado por SÁNChez CANTón, F.J. (ed.): Inventarios Reales. Bienes muebles que pertenecieron a Felipe II, Archivo Documental Español, XII, Madrid, 1956-59, no se menciona ningún Socrates, pero sí varios Césares y «Otra estatua de medio cuerpo, de relieve, de mármol, de Aníbal Cartaginés, la cabeza de mármol blanco antigua y el pecho y pedestal de jaspe amarillo. Tasado en trescientos ducados», p. 181, 3.614. Entre los orígenes de los lotes, no se nombra a Pío IV.

${ }^{69}$ Este mismo año Felipe II recibe una tentadora oferta de Alessandro Corvino quien le propone la compra de su escogida colección compuesta por multitud de monedas antiguas, camafeos, pequeños bronces, pinturas y esculturas. La alta calidad de las mismas merecen que reproduzcamos estos dos últimos apartados: "Cose varie di Marmo/ Una testa di basso rilievo di Antinoo/ Un Torso di Venere di un palmo et mezzo/ Un Torso di bacco con la sua base poco piu di un palmo/ Una Testa di Tigre sopra una Zampa d'Alabastro/ Una Testa con il petto d'Alessandro Pio alta circa un palmo/ Una Testa di Giove, col petto della medema altezza d'Alabastro/ Una Testa di un Sileno grossa, quanto un gran pugno/ Una testa di Antinoo alla greca, quanto il naturale/ Una Testa di un Phauno coronato d'helera, raro/ Una Testa di una Venere, bellal Una Testolina di una Roma/ Una Testolina di una Vergine Egiptial Una Testolina di una Venere/ Una figurina ignuda, con le gambe rifatte modernamente/ Un Torso di un fauno, in bellissima attitudine/ Una feminetta, che se difende da uno che 
a manos de Felipe II. No sería descabellado pensar que estos regalos buscasen despertar en Felipe II el interés por la escultura ${ }^{70}$, algo que no se logrará plenamente hasta que decida ornamentar El Escorial, ocasión en la que, cumpliéndose los pronósticos de Granvela de tantos años atrás, recurrirá, por fin, a los Leoni.

\section{APÉNDICE DOCUMENTAL}

I. Minuta del obispo de Arrás a Leone Aretino, Bruselas, 10 de febrero de 1557, Biblioteca de Palacio (B.P. ), Madrid, Ms. II/2264, f.34v.

\section{Mag ${ }^{\mathrm{co}}$ signor}

mi rincresce sin allanima delli disagii incommoditadi et molto piu della infirmita sopragionti a v.s. in cotesto suo viaggio/ ma mi consolo al quanto d'interder per la soa di 24 del passato che stesse gia meglio, et non si maravigli se de tanti [tachado: et tali] occorsili insieme mali non si puo cosi agevolmente rihavere come vorrebbe/ pur io spero ch'[tachado: poi che si trova gia/trovandosi] essendo gia gionto a casa soa [tachado: propia] et tra li suoi dove havera miglior commodita di farsi trattare et servire potra ben presto esserne del tutto libero [tachado: inteder che sia del tutto sano/ Il che faccia Iddio] Iddio'l faccia cosi/et v.s. sia pur certa che dove io la potro giovar [tachado: non si scordi mai di me che li son[o] tanto amico come sa /et mi facci alle volte saper di soe nove/ne di comandarmi sempre quel che gli occorrera poi che sa che non ha amico ne piu amorevole ne piu affettionato] et servirlo lo faro sempre co'l medesimo amore et volonta che per la dietro.

[tachado: Io gli mandai subito da fin gante] et conforme acio g'i mandai subito da fin gante quelle lettere che ricercava per Il $\mathrm{R}^{\mathrm{mo}}$ di trento ${ }^{71}$ in raccomendatione del cavalier vendramino/et per Il presidente del senato sopra l'uffitio dusciero in

la tirava, per li panni/ Una Dea della Natura tutta di marmo bianco/ Una Dea simile, ma con la faccia come di bronzo, alte l'una et l'altra, doi palmi in circa/ Una Venere vestita di panni sottili, alta circa quattro palmi/ Un Torso di Apollo, in atto di sanare/ Un cerchio di Porfido vacuo, che puo servire per base al detto Apollo/ Un Quadro di tre o quattro palmi in circa di lunghezza, dove sono tre figure di basso rilievo, giudicato per il sacrifitio di Iphigenia dove, siede il Padre, col capo velato, opera di maestro eccellente / Quadretti di Pittura/ La Cena di Leonardo Vinci gia fatta à Milano, ritratta in piccolo dalla propia/ Un'inverno di quel maestro della Civetta/ Una Notte con fuochi, dell'istessa mano/ Un'altra notte dell'istessa mano/ Una Primavera con S. Hieronimo dell'istessa mano/ Un'altro Paese pui grandetto con la favola di Acteon, et Diana, del medesmo/ Un Paese di mano di un maestro eccellente vecchio/ Un Paese grande il doppio con S.Hieronimo/ Un Quadro alto circa tre palmi, con una Nostra Donna Giudicato in Venetia da ms Titiano homo eccellente per mano di Leonardo Vinci già concorrente di Miche'Angelo, homo famosiss ${ }^{\circ}$ et già chiamato dal Re Francesco, con honoratissima provisione, appresso del quale mori», Alessandro Corvino a Fernando de Torres, Roma, 3 de enero de 1561, A.G.S., Estado, Roma, leg.889, 120 y 121 (inventario). Aunque la extensión del artículo impide un análisis más pormenorizado, no queremos dejar de señalar que muchas de estas piezas terminarán en la colección del cardenal Farnesio, quien no desaprovecha la oportunidad de comprarlas ese mismo año (Lanciani, R.: Storia degli scavi di Roma, 1902, II, pp. 16264, amén de numerosas referencias en su correspondencia y en la de Fulvio Orsini o Carlo Gualteruzzi, a obras procedentes de la colección de Corvino) o en la de Maffei quien adquiere varias obras de Corvino a su muerte en enero de 1562 (Greco, A.: «San Filippo Neri in una lettera inedita di Annibal Caro», en Rivista di storia della Chiesa in Italia, IX (1955), pp. 260-74). También queremos resaltar la importancia del malagueño Fernando de Torres, quien visita España en 1561, que actuará frecuentemente como agente en Roma para adquirir obras de arte destinadas a los virreyes de Nápoles, especialmente con el duque de Alcalá y, posteriormente, con el propio cardenal Granvela. Cuando Granvela pida a Leoni que le informe de qué medallas antiguas están en ese momento en venta en Roma, el escultor le responderá que las que posee su amigo el anticuario Corvino, al que escribirá para iniciar las negociaciones y que envíe una lista de las que dispone (cartas de L.Leoni al obispo de Arrás, Milán, 14 y 15 de marzo de 1561, en Plon, E.: op. cit., 1887, pp. 384 y 385, 72 y 71 . Su ubicación actual es B.P., Ms. II/2275, ff.124-5 y 126. El estudioso francés fechaba la primera de estas cartas en mayo, cuando ambas son escritas en marzo).

${ }_{70}$ También, estos presentes diplomáticos buscarían abonar el terreno para conseguir el favor del monarca. Prueba de esto es la minuta de una carta que escribe el embajador español en Roma, don Juan de Zuñiga, a Felipe II el 17 de marzo de 1570, en la que, al comentar las pensiones que repartió Pío V entre los cardenales, le comunica la insatisfacción de Montepulciano al no ser beneficiario de ninguna, a pesar de los apoyos con que contaba entre los cardenales y del regalo que hizo al monarca casi un decenio antes del que parece no haber recibido ninguna contrapartida: «montepulchano me han [tachado: dicho algunos] que estava sentido yo [tachado: he hecho] hize con el cumplimiento porque ha sido grande la afficion que siempre ha tenido al servicio de v.Mg [tachado: y creo que con los presentes que ha hecho de mesas de piedra y otras cosas montan mas que valdria la pension que se le podia dar aunque fuera renta que se pudiera comprar] el esta pobre [tachado: desto cosas] y por las fabricas que haze y por las cosas que ha dado $q^{a}$ V.M ${ }^{d}$ aun creo que le ha cabido parte de los marmoles y mesas de piedra que embio una vez que le costaron buen dinero y pocos dias antes que viniese el nombramiento de las pensiones me dio a entender que estava con necesidad con gana que lo rrepresentase a v.Mg ha quedado agora satisfecho con que yo le he asegurado la voluntad y afficion que v. Mg. le tiene y la necesidad que avia de cumplir esta vez con los otros...», British Library, Additional Ms.28405, f.237r.

${ }_{71}$ Gobernador de Milán antes que Gonzalo Fernández de Córdoba, duque de Sessa. 
favor di battista rosato havendo insieme scritto a ms. massimo del pero ${ }^{72}$ ch'egli a nome mio ne parlasse co'l detto presidente et mi pare che le lettere furono mandate al patanella ${ }^{73} / \mathrm{o}$ veramente al detto $\mathrm{ms}$. massimo/et anchora ch'io spero ch'a arrivo di questa v.s. l'havera gia ricevute niente di manco gliene manco [tachado: con] adesso il duplicato de tutte tre accio non essendo comparse l'altre Il ch'io non posso credere si valere di queste/Et Iddio la conservi prospera et felice, da brussellas alli 10 di febraro 1557 .

\section{Carta de Leon Leoni al obispo de Arrás, Milán, 18 de marzo de 1557. B.P. , Ms.II/2270, f.253.}

Ill $^{\text {mo }}$ et $\mathrm{R}^{\text {mo }}$ Mons s mio

Potete pensar di che contentezza si sia stata la lettra da v.s. scrittami con tanto amore, et amonimento, io non mancherò di perseverme et di farmi honore, et di compiacer a v.s. di quanto la desidera piu per mio beneficio che per suo pensiero o deletatione, circa il voler sapere come mi possa risolver presto del rinettare de le statue di metalo gia fondute non so che risponder a v.s. sino che saran quanto piutosto sara posibile rinettare et tanto piu presto quanto non si me manchera di aiuto il quale per lo passato è stato debole. pur perche mi credo che v.s. Ill ${ }^{\mathrm{ma}}$ ansi vederà a miei bisogni come sempre ha fatto credo che dentro da uno anno potro darle fornite del tutto, ma poi chel Sor Don ferando [Ferrante Gonzaga] ni ha domandati i picioli schissi del'opere per mostrarli a sua $\mathrm{M}^{\text {ta }}$ et perche credo al fermo che la gli vederà io me rimetero a quanto vi referirà il detto $\mathrm{s}^{\text {or }}$ io gli havrei mandato anchor[a] a v.s. Ill $^{\mathrm{ma}}$ ma portavano temp $\mathrm{p}^{\circ}$ et io no ho molto, ma tanto sarà et per far fine basciarò le mani di v.s.Ill ${ }^{\text {ma }}$ pregando iddio che la conserve come desidera/ $\mathrm{Da} \mathrm{Mil}^{\circ} 1557$, il 18 de marzo

D.V.s.IIl ${ }^{\mathrm{ma}}$ e $\mathrm{R}^{\mathrm{ma}}$ servitor/Leone Are ${ }^{\text {no }}$

\section{Minuta del obispo de Arrás a Leon Aretino, Bruselas, 12 de diciembre de 1557. B.P. , Ms. II/2549, f.173.}

\section{Molto mag ${ }^{\text {co }}$ signor}

mentre eramo alla guerra ricevei [tachado: una] la lettera di v.s. de 29 di giugno con una alligata per pompeo suo figlio la quale mandai a buon ricapito et sin adesso io non ho [tachado:mai] inteso [tachado: cosa ne] del detto suo figlio [tachado: anzi che non] se non ogni bene anzi spero si comportera sempre come v.s. [tachado: lo] desidera [tachado: et se non ho prima ch'ora risposto] la quale se non gli ho risposto prima ch'hora imputilo al haverlo io voluto servire in quello che ricercava [tachado: sopra] per la consignatione del residuo della soa pensione che non gli era stato consegnato, Il che non [tachado: havendo] essendo si potuto spedir nella guerra dove [tachado: come v.s. si trottava] s'attende ad altro ch'a negotii de particolari e stato bisogno aspettar sin che semo ritornati qua [tachado: et] pur adesso gli mando [tachado: a v.s.] una lettera per Il governatore di cotesto stato sopra la detta [tachado: assegn(atione)] consignatione, come v.s. vedera per l'alligata copia, et sempre ch'in altro [tachado: in altra cosa io] l'a possa io [tachado: adoperar per lei far] con piacere [tachado: in altra cosa] mi trovera prontissimo, certificandola che mi e [tachado: dispiaciuto] doluto sin all' anima della soa Indispositione, essendomi non manco r'allegrar[guillotinado: mi] d'intender per esse soe lettere, che stesse gia meglio, Il che spero si sara continuato, onde io ne prego'l $\mathrm{s}^{\text {re }}$ et gli dia sempre ogni ben et contentezza, da bruss. alli 12 di decembre 1557.

IV. Minuta del obispo de Arrás a Juan Vázquez [s.l.; s.d. 8 de mayo de 1558], B.P. , Ms. II/2261, f.206v.

Muy magco señor:

quando el Emperador y las rreynas se fueron a españa fue con ellas un hijo de leon aretino sculptor singular como v.m. havra entendido, y el hijo es de tal ingenio y [tachado: tenia ya tambien] llevaba ya tal principio que se podia con el tiempo sperar del no menos que del padre he entendido que por algunas livianidades que ha dcho le tienen en la inquisicion, Suplico a v.m. que considerando que es moço y que no ha quiça pensado lo que dezia ni lo que havra dcho con malicia y fundam $^{\text {to }}$ sino por pura livianidad y locura, sea servido [tachado: que] queriendose el arrepentir y someter favorecerle con quien fuere menester de manera que si es posible no se le haga daño ny afrenta. antes toda la gracia y md. que [tachado: en ella recibire yo muy gra] huviere lugar que allende que se hara en esto muy grande al padre y la merece por su arte y abillidad y por lo mucho que en ella ha servido a sus magdes, y se halla afligidissimo por esta desgracia del hijo

me obligara a mi en ello muy mucho v.m. cuya----y casa---- de----

\section{Minuta del obispo de Arrás a Leon Aretino, Cambrai, 14 de mayo de 1558. B.P. , Ms. II/2261, ff.208-209.}

Molto mag ${ }^{\mathrm{co}}$ signor

Io ho piu volte parlato al re sopra le cose di pompeo, ma fin[o] qui non ho potuto ricavar di bocca sua che voglia far offitio con li Inquisitori, et non me ne maraviglio sapendo io quanto rispetto i principi di spagna portano et con molta raggione alla Inquisitione, dico tanto che me ricordo a tempo mi haver veduto un Imbassatore del re d'inghelterra in molto pericolo, non volendo et son[o] per $\operatorname{dir}[\mathrm{e}]$, non potendo soa $\mathrm{ma}^{\text {ta }} \mathrm{Ces}^{\mathrm{a}}$ aiutarlo, et è di bisogno che cosi si faci in quelle parti

72 Secretario de asuntos italianos del obispo de Arrás.

${ }_{73}$ M.A. Patanella era el ecónomo de Milán. 
et si usi di tanto rigore, perche mi dubito che altrimente le cose della religione anderebbero male la, dove hoggi per dio gratia è la prionetta(?) provintia che si trovo di queste nove opinioni, ma pur per non manchar vi ne al detto pompeo come non faro mai in quanto potro con la ragione ho scritto al sor giovan vazques molto calda ${ }^{\text {te }}$ supplicandole che per tutte le vie che vedera poterlo aiutare lo [tachado: far] aiuti come mi rendo certo che fara et se quello ha peccato sara solam ${ }^{\text {te }}$ da leggiero tutta la pena sara Il disdirsi, ma siate pur certo che altrimente, et volendo egli restar ostinato nel sostener quelle cose da lui non intese non basterebbe nessuno a poterlo salvar di pericolo Iddio per soa gratia facci che si lassi condurre al dovere senza restar pertinace [tachado: ostinato] quanto a quelle statue et Imagini che v.s. ha fatto doppo la ritornata son[o] di la, come voi sapete questo $\mathrm{p}^{\mathrm{e}}$ piglia piu dilettatione nella pittura che nella scultura, per dove volendolo inclinar a farlo desideroso di quelle vre opere saria bisogno haverne di biancho oscuro qualche ritratto che li facesse venir la voglia di vederle, et fari pur che non tardi ch'io per me non manchero al offitio, et con questo di cuore me gli offero et raccomando da cambrai alli 14 di maggio 1558.

\section{Minuta del obispo de Arrás a Leon Leoni, Bruselas, 12 de junio de 1558. B.P. , Ms.II/2261, f.244v.}

Molto mag ${ }^{\mathrm{co}}$ signor

ho ricevuto la di v.s. di 27 (?) del passato et rallegrato mi sommamente della liberatione del figluolo per il quale Io haveva gia scritto al $\mathrm{s}^{\text {or }}$ gio vazquez come per altre mie haverete visto, et spero che questa paura gli servira d'essempio per andar un'altra volto piu ritenuto nel suo giovenile et sfrenato parlare, et v.s. gli deve dar una buona lettione et fargli conoscer ch'egli non si deve stimar per piu savio in queste cose della religione che molti altri che lo sono stati piu di lui, et ch'hanno comprobatione et vera dottrina delli antichi padri tante et tante volte per tutte le nationi del mondo in diversi concilii disputata et confermata, ma che servendo a Iddio attenda alla soa arte et lavor senza Impacciarsi piu oltre, et fara charo a v.s., et anche a me che gli voglio bene, et con questo facendo fine preggo Iddio vi guardi di male da brusselles alli 12 di giugno 1558

\section{Minuta del obispo de Arrás a Leon Leoni, Sercamp, 3 de noviembre de 1558. B.P. , Ms.II/2304, f.[218].}

a leon

aretino Molto $\mathrm{mag}^{\mathrm{co}}$ signor

adesso ho ricevuto la lettera di v.s. di 8 di luglio, non so dove ella habbi indugiato tanto, pur mi sono r'allegrato d'intender [tachado:dere] che l'Ill ${ }^{\mathrm{mo}}$ duca di Sessa havesse chiamato v.s., et visto delle cose soe, che son[o] certo gli haveran piacciuto, essendo esse tali che meritano ogni laude, quanto alla medaglia mia che soa ecc ${ }^{\mathrm{a}}$ piglio, Io lo reputo a favore, et ritornando con l'aiuto d'Iddio a brussellas, perche mi trovo adesso qui su questo negotio della pace, io vedero di mandargliene unaltra che sia ben gettatta, et parimente una dell'imperatrice come [tachado:v.s.] dice perche la desidera, et se a v.s. posso far piacer alcuno, gia sa che le sono affettionato, et puo esser certa ch' m'adoperero sempre per lei [tachado:molto] non manco voluntieri, che per Il passato, et Iddio le dia quelche desidera, da sercamp alli 3 di novembre 1558 .

\section{Minuta del obispo de Arrás a Leon Aretino, Bruselas, 4 de mayo de 1559. B.P., Ms. II/2320, f. 2.}

a leon aretino

Molto mag $^{\text {co }}$ signor

la di v.s. del primo del passato ho ricevuto et parlato co'l $\mathrm{Ill}^{\mathrm{mo}}$ duca d'alva in conformita di quel che mi scrivete circa l'andata vra in Spagna, dice che vi si rimette, et che la cagione era solamente per fornire quelle cose ch'ivi sono gia cominciate, et poi che non essendovi altro bastera pompeo suo figlio, pareria come amico che le sono che non saria di bisogno che v.s. ci [tachado: vada] andasse, io vedo'l nro Re curarsi pocco per adesso de la scultura et l'animo suo esser piu inclino all' [tachado: archi] pittura et architettura, le quale forze potrebbe reccar cagione volendo soa $\mathrm{Ma}^{\text {ta }}$ far alcuni grandi edifitti et metterci statue, o medaglie ch'havessero anchora un giorno bisogno dell'opera di v.s., et in simil caso le consiglierei ben io di mettersi in qualsivoglia disaggio per non manchar di servir un tal $\mathrm{p}^{\mathrm{e}}$ et patrone come'l nro, ma per hora non essendo pui necessaria che tanto la presentia soa di la, mi pare che si deve star queto, pur lei si risolvera a quello che guidichera'l meglio, et occorrendo cosa in ch'io la possa giovare sia certa che mi trovera sempre prontissimo a farlo molto voluntieri, et con questo tutto me le offero et raccomando, Da brusselles alli 4 di maggio 1559.

\section{Minuta del obispo de Arrás a Leon Aretino, Gante, 30 de julio de 1559, B.P. II/2320, f. 106.}

a leon molto mag ${ }^{\text {co }}$ signor

ho ricevuto la di v.s. di 18 di questo, et mi è dispiaciuto assai del [tachado: garbug] imbroglio travenuto vi in casa [tachado: fin qu io] non ne udito [tachado: molto] fino qui motto nessuno in questa corte. pur ho acharo desser avertito delle giustificationi et escuse di v.s., accio ch'essendo di bisogno io possa risponder per lei come convenga, et sia certa che senza ceremonie alcune mi troverà sempre prontissimo a farle piacer et servitio, soa ma ${ }^{\text {ta }}$ se ne va in spagna, ma io mi resto qui, a godere si potrò qualque poco di riposo, dappo tante fattiche et travagli qua [guillotinado] ogniuno fa che nel servitio 
del [guillotinado] lor $\mathrm{ma}^{\text {ti }}$ ho passato et sofferto et con questo a v.s. tutto mi offero et raccomando, da gante alli 30 di luglio 1559

X. Minuta del obispo de Arrás a Leon Aretino, Bruselas, 29 de julio de 1560. B.P. , Ms.II/2305, f.126.

Molto mag $^{\text {co }}$ sig $^{\text {re }}$

ho havuto la di v.s. di 22 del passato, e mi r'allegro con essa lei d'intender che sia stato cosi ben visto, racolto, et accarezzatoda soa san $^{\text {ta }}$, et dalli suoi, ma non inmeritamente rispetto all'eccellentia dell'arte soa, et mi r'allegro anchora di che, habbian cominciato adoperarla, [tachado: essendo io certo] cosi per l'utile, et commodo suo, come anche per che so, che d'ogni cosa, che se le metta nelle mani ne riuscira con honore, io non le ho piu qui domandato l'effigie di S.San ${ }^{\text {ta }}$, perche non solo non sapevo che v.s. l'havesse cavata, et havendolo fatto et so che l'havera meglio indovinata da nessun'altro, ma ne anche sapevo che fusse in Roma, hora dico che mi farete un piacere grandissimo in mandarmela, solamente in piombo, perche la desidero sommamente, et l'havevo gia fatto cercare in ogni banda, o di rilievo, o in pittura, o di [tachado:qualsi voglia] qualunque sorte che fusse [tachado: solo ch'io la potessi havere, essendo io] perchel ch'io sono sempre stato [tachado: cosi] affettionato servitore di soa San ${ }^{\text {ta }}$, et delli suoi, come ogni uno sa, et havendola qua in piombo ne potro far gettar in argento et in oro [tachado: et argento] et farle gettare conforme al piombo Ho gia scritto a spagna, accio che s'intenda la volonta di soa $\mathrm{Ma}^{\text {ta }}$ circa quello ch'appontate di voler oprar con Michel Angelo, che facesse qualque disegno per la sepoltora del nro Invittissimo imperatore Carlo di fe: me:, ma che bisognarebbe, che soa Ma ${ }^{\text {ta }}$ gli scrivesse un motto, o al manco a v.s. cosa che li potesse mostrare, vedremo quel che risponderanno, che veramente a me parebbe degno, che da un tal huomo si procurasse, con ogni sforzo di [tachado: havere] cavare una simil cosa, et non occorrendomi per adesso altro, faro fine con pregar Iddio vi conservi, Da Brusselles, alli 29 di Giulio 1560. 